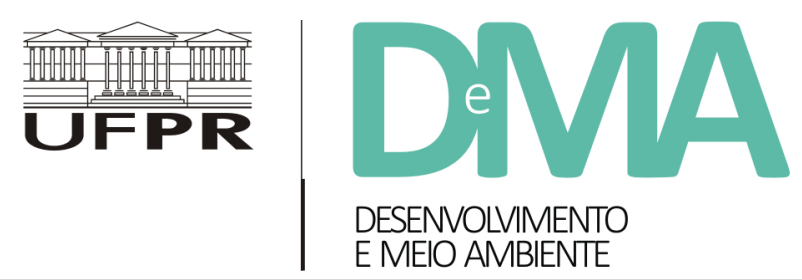

\title{
Avaliação dos Zoneamentos Ecológico-Econômicos Costeiros (ZEEC) do Brasil: proposta metodológica
}

\section{Evaluation of Coastal Ecological-Economic Zoning (ZEEC) in Brazil: Methodological Proposal}

\author{
João Luis NICOLODI ${ }^{1 *}$, Milton ASMUS ${ }^{1}$, Alexander TURRA², Marcus POLETTE ${ }^{3}$ \\ ${ }^{1}$ Universidade Federal de Rio Grande (FURG), Rio Grande, RS, Brasil. \\ ${ }^{2}$ Universidade de São Paulo (USP), São Paulo, SP, Brasil. \\ ${ }^{3}$ Universidade do Vale do Itajaí (UNIVALI), Itajaí, SC, Brasil. \\ *E-mail de contato: joaonicolodi@furg.br
}

Artigo recebido em 28 de agosto de 2017, versão final aceita em 12 de dezembro de 2017.

RESUMO: O Zoneamento Ecológico-Econômico Costeiro (ZEEC) vem sendo elaborado e implementado desde 1988 em diversas escalas de trabalho e em frações do território nacional, com o objetivo de efetivar ações de gestão ambiental e territorial integradas. Os diversos contextos históricos, políticos, econômicos e ambientais em que os mesmos foram criados denotam diferentes graus de efetividade do instrumento. Com a intenção de realizar inédita avaliação quantitativa e qualitativa sobre este instrumento, o Ministério do Meio Ambiente, em parceria com as Universidades Federal de Rio Grande (FURG), Universidade do Vale do Itajaí (UNIVALI) e Universidade de São Paulo (USP), desenvolveu um arcabouço metodológico que buscou aliar a base técnica de informações disponíveis com a percepção de atores sociais preponderantes no processo. Tal método, desenvolvido dada a inexistência de referências metodológicas específicas para este tipo de análise, é aqui apresentado sob a ótica dos resultados obtidos com a avaliação dos ZEE costeiros no país. Foram executadas as seguintes etapas: 1 - Pré-planejamento; 2 - Análise documental, com a construção de um sistema compartilhado de armazenamento de arquivos sistematizados; 3 - Elaboração de um Sistema com 35 Indicadores específicos; 4 - Elaboração e aplicação de entrevistas semiestruturadas em 16 estados costeiros do Brasil; 5 - Aplicação da Escala Lickert aos indicadores; 6 - Análise individualizada dos indicadores por meio de fichas de avaliação específicas; 7 - Workshop de validação realizado com a presença de representantes dos estados costeiros; e 8 - Análise integrada dos indicadores. Os resultados apontam, se não para um cenário favorável, para uma situação de consolidação e de maturidade do instrumento de gestão, embora não de forma homogênea, ao longo da costa brasileira. Tal cenário diagnosticado não indica, necessariamente, uma melhor condição socioambiental em determinado território, efeito certamente desejado em tal contexto. A estratégia 
metodológica aplicada apresentou-se como satisfatória no que tange à obtenção e à análise do ZEE. Como sugestão para aplicações futuras do método, sugere-se a revisão de determinados indicadores, principalmente no que diz respeito às entrevistas semiestruturadas, as quais por vezes não refletiram a necessidade de alimentação do indicador, bem como a transposição da premência da consecução do mesmo.

Palavras-chave: Zoneamento Ecológico Econômico; zona costeira brasileira; planejamento ambiental; gerenciamento costeiro.

ABSTRACT: Coastal ecological and economic zoning (ZEEC) has been elaborated and implemented since 1988 in various scales and in fractions of the national territory with the objective of carrying out integrated environmental and territorial management actions. The diverse historical, political, economic and environmental contexts in which they were created denote their different effectiveness degrees. With the intention of carrying out an unprecedented quantitative and qualitative evaluation on this instrument, the Ministry of the Environment, in partnership with the Federal University of Rio Grande (FURG), Vale do Itajaí University (UNIVALI) and University de São Paulo (USP), developed a methodological framework that sought to combine the technical base of available information with the perception of social actors preponderant in the process. This method, developed given the lack of specific methodological references for this type of analysis, is presented here from the perspective of the results obtained with the evaluation of coastal EEZs in the country. The following steps were performed: 1 - Pre-planning; 2 - Documental analysis, with the construction of a systematized database; 3 - Elaboration of a system with 35 specific Indicators; 4 - Elaboration and application of semi-structured interviews in 16 coastal states of Brazil; 5 - Application of the Lickert Scale to the indicators; 6 - Individual analysis of the indicators by means of specific evaluation sheets; 7 - Validation workshop conducted with the presence of coastal states representatives; and 8 - Integrated analysis of indicators. The results indicate, if not to a favourable scenario, to a situation of consolidation and maturity of the management instrument, although not in a homogeneous way, along the Brazilian coast. Such diagnosed scenario does not necessarily indicate a better socio-environmental condition in a given territory, certainly the desired effect in this context. The methodological strategy applied, although it demanded a much longer time than originally planned, was satisfactory with regard to the collection and analysis of the EEZ. As an observation for future applications of the method, it is suggested the revision of certain indicators, especially with respect to the semi-structured interviews, which sometimes did not reflect the need to feed the indicator, as well as the transposition of the urgency of achieving the same.

Keywords: Ecological and Economic Zoning; Brazilian coastal zone; environmental planning; coastal management.

\section{Introdução}

O zoneamento ecológico-econômico (ZEE), instrumento da Política Nacional do Meio Ambiente (PNMA), tem sido implementado pelo poder público em diversas escalas de trabalho e em frações do território nacional. Municípios, estados da federação e órgãos federais têm executado ZEEs e avançado na conexão entre os produtos gerados e outros instrumentos de políticas públicas, com o objetivo de efetivar ações de gestão ambiental e territorial integradas.

O zoneamento é também considerado no Plano Nacional de Gerenciamento Costeiro, instituído pela Lei 7.661/81, que no Art. $3^{\circ}$ indica que o mesmo deverá ser previsto para usos e atividades da zona costeira, priorizando a conservação e a 
proteção dos recursos naturais, renováveis e não renováveis. A regulamentação, por meio do Decreto 5.300/2004, indica que cabe ao ZEEC - Zoneamento Ecológico-Econômico Costeiro - orientar o processo de ordenamento territorial da costa, garantindo as condições para o desenvolvimento sustentável dessa porção do território, mediante o apoio às ações de monitoramento, licenciamento ambiental e elaboração de instrumentos econômicos para a gestão ambiental, dentre outras.

O Zoneamento Ambiental previsto na PNMA e o Zoneamento Costeiro têm trilhado caminhos distintos, com produtos elaborados em diferentes feições e escalas, carecendo, no entanto, de uma visão mais integrada do território que considere, inclusive, o ambiente marítimo como parte integrante do território nacional.

Com relação ao uso dos espaços naturais continentais e marítimos do país, observa-se uma histórica deficiência de planejamento e ordenamento territorial. Essa tendência resultou na disputa por espaços entre diversos setores da sociedade, gerando significativos impactos sociais e ambientais em diferentes escalas. $\mathrm{O}$ gerenciamento destes impactos é de extrema complexidade e necessita de mecanismos e instrumentos técnicos e políticos que garantam sua interpretação integrada e soluções compartilhadas entre os entes federativos, com ampla participação dos atores envolvidos, atuando de forma preventiva (onde ainda for possível) e corrigindo as distorções onde for necessário.

No caso específico da zona costeira, onde reside cerca de $26 \%$ da população brasileira (IBGE, 2010), os estuários e a orla constituem áreas particularmente sujeitas a vetores de desenvolvimento em franco processo de expansão (MMA, 2008). Tais vetores têm contribuído para acelerar a ex- pansão urbana irregular, com todos os problemas e impactos dela decorrentes, como o lançamento de esgotos e efluentes industriais costeiros e continentais e a ocupação de áreas públicas e de preservação permanente, em um ambiente marcado por um complexo mosaico de ecossistemas e uma enorme biodiversidade, materializados em diversas paisagens (Jablonski \& Filet, 2008).

As diversas atividades econômicas concentradas na porção continental do território afetam direta ou indiretamente os ambientes costeiros e marinhos. Como exemplo, cita-se o turismo, que gera um fluxo sazonal de pessoas e de capital para as regiões costeiras na alta temporada, causando impactos significativos na distribuição de água e energia elétrica, descarte de efluentes e coleta de resíduos. Outros exemplos são as indústrias de alimento, têxtil, siderúrgica, entre outras que têm, em sua maioria, atividades de extração de recursos e de produção localizadas em regiões continentais interiores, mas dependem diretamente das estruturas viárias e portuárias para o escoamento dos produtos e para a aquisição de insumos. Elas utilizam os corpos d'água como receptores de seus efluentes que, dependendo da bacia de drenagem em que estão instaladas, podem prejudicar, limitar ou até inviabilizar outros usos à jusante, como captação de água para abastecimento público, agricultura, pesca e atividades de lazer (Coccossis et al., 1999).

O destino final da maior parte das substâncias descartadas em cursos d'água ao longo das bacias hidrográficas é o ambiente marinho. Este possui elevada capacidade de depuração, principalmente em locais com alta hidrodinâmica, onde a constante troca de água promove as rápidas dispersão e diluição de poluentes. Porém, o que se tem observado em diversas regiões do país e do mundo é que esta 
capacidade de depuração parece ter chegado ao limite (Coccossis, 2004), comprometendo o equilíbrio dos ecossistemas, devido ao grande aporte de contaminantes oriundos de fontes diversas, tanto continentais como costeiras e marinhas. Adiciona-se a isto o aporte de resíduos sólidos, em especial materiais plásticos, que se decompõem lentamente no ambiente natural e não são diluídos (UNEP, 2016).

O cenário atual demonstra a necessidade de planejamento e ordenamento dos diferentes usos e atividades identificados na Zona Costeira. O Zoneamento Ecológico-Econômico Costeiro é o instrumento legal para orientar a revisão e os novos processos de ordenamento territorial da costa, garantindo as condições para o desenvolvimento sustentável dessa porção do território (Asmus et al., 2006). Portanto, avaliar a implementação e compreender os elementos que favorecem ou dificultam sua implementação são pontos estratégicos no aprimoramento desse instrumento de gestão.

Do ponto de vista de experiências em avaliações qualitativas e quantitativas aplicadas ao ZEE no país, destacam-se principalmente as consultorias encomendadas pelo poder público e alguns trabalhos acadêmicos específicos. Embora exista um considerável conjunto de documentos e artigos científicos que propuseram algum tipo de análise ao processo do Zoneamento Ecológico-Econômico - ZEE (Ab'Saber, 1989; Ranieri, 2000; Schubart, 2000; Gandra, 2008; Oliveira, 2004; Lima, 2006; Montaño et al., 2007), o recorte territorial da zona costeira, seja aquele estabelecido por Lei ou alguma outra proposição, se faz presente apenas em uma minoria destes estudos.

Santos (2010) propôs critérios para avaliação de zoneamentos ambientais como instrumento de planejamento e ordenamento territorial. Em seu trabalho, a autora define cenários considerados ótimos para algumas especificidades do processo de Zoneamento e os enquadra frente a estudos de caso específicos. A autora utilizou três zoneamentos específicos: Zoneamento Ambiental de Brotas (SP), Zoneamento Ecológico-Econômico do Litoral Norte de SP e o Zoneamento Agroambiental do setor sucroalcooleiro de SP.

Outros exemplos de pesquisas acadêmicas que abordaram aspectos específicos do ZEE são os trabalhos de Leite (2001), que abordou o processo de implementação do Zoneamento Ecológico-Econômico, enquanto instrumento de Gestão Ambiental para fins de ordenamento do território, mas especificamente da Amazônia Legal; Bastos e Silva (2010), os quais analisaram o ZEE como subsídio aos procedimentos de licenciamento ambiental na Zona Costeira do Estado do Ceará; Ferreira (2011), que fez uma avaliação do zoneamento ecológico-econômico no município do Rio de Janeiro como ferramenta para a gestão territorial integrada e desenvolvimento sustentável; Araújo et al. (2011), que analisaram o Zoneamento Ecológico-Econômico enquanto instrumento de planejamento ambiental que antecede o planejamento urbano; Vasconcelos et al. (2013), onde os autores discutem as finalidades e utilidades do Zoneamento Ecológico-Econômico, sob a ótica dos fundamentos de interação entre as áreas de Economia e Ecologia e o contexto dos planejamentos ambientais de uso do solo. Quiçá a publicação de Ogata (2015) seja a que discute mais especificamente o ZEE como um instrumento de regulação do território no Brasil, ressaltando o "peso" deste instrumento frente às políticas de ordenamento territorial.

Já no âmbito do poder público, algumas iniciativas são relevantes. Destaca-se o trabalho de 
Del Prette \& Matteo (2006), onde é discutida a situação do Zoneamento Ecológico-Econômico no Brasil. Essa publicação encontra-se no Caderno de Referência: subsídios ao debate, do Ministério do Meio Ambiente. Outra iniciativa que produziu um denso material de referência foi a publicação da transcrição dos debates da consolidação da metodologia do ZEE para o Brasil (MMA, 2002).

Também é de relevância o consistente esforço de avaliação do Zoneamento Ecológico-Econômico no Brasil realizado em 2010, vinculado ao edital BRA10-11204/2010 e firmado entre o PNUD e a empresa Kampatec Assessoria e Consultoria Ltda., bem como a avaliação realizada sobre o Zoneamento Econômico-Ecológico na Amazônia Legal, publicado pelo Ministério do Meio Ambiente em 2016 (MMA, 2016).

Face à problemática exposta, o presente artigo ${ }^{1}$ apresenta, com base em uma revisão atualizada dos ZEECs executados até o ano de 2016, uma proposta de aperfeiçoamento metodológico para avaliação da implementação do instrumento que favoreça o entendimento de processo e de resultado e, consequentemente, as potencialidades e vulnerabilidades do território. Tal análise demanda o desenvolvimento de um método específico que aglutine tanto uma análise referenciada nos marcos legais e teóricos quanto nas percepções e reflexões dos atores envolvidos (entrevistas), uma vez que não existem métodos padronizados que analisem qualitativa e quantitativamente os processos de elaboração e de implementação dos zoneamentos ecológico-econômicos costeiros conduzidos no país. Essa proposta metodológica busca contribuir, em última análise, para a evolução estratégica e metodológica do zoneamento ecológico-econômico costeiro do território nacional, em suas feições continental, costeira e marinha.

\section{Método}

O método proposto para essa avaliação partiu do pressuposto da insuficiente oferta de arcabouços metodológicos de avaliação de um instrumento de política pública com características peculiares como o ZEEC, o qual possui, ao mesmo tempo, nuances de ordenamento territorial e planejamento estratégico, com forte possibilidade de interação com mecanismos de comando e controle. Além disso, não se buscou analisar os produtos gerados pelo instrumento apenas em relação à sua qualidade técnica. A presente avaliação focou também no processo como um todo, tendo como base orientadora o fluxograma de fases e processos previsto no documento Diretrizes Metodológicas para o ZEE (MMA, 2006) (Figura 1).

\subsection{A construção do método}

Em função do seu escopo, pode-se enquadrar a presente análise na categoria das "pesquisas exploratório-descritivas", a qual prescinde de algumas etapas básicas: levantamento bibliográfico, consulta a especialistas sobre o objeto da pesquisa, análise de casos e aplicação de técnicas padronizadas de coleta de dados, como entrevistas e questionários semiestruturados (Gil, 1987).

\footnotetext{
${ }^{1}$ Este artigo é resultado de projeto desenvolvido pela Universidade Federal de Rio Grande (FURG), Universidade do Vale do Itajaí (UNIVALI)
} e Universidade de São Paulo (USP), sob a coordenação do Ministério do Meio Ambiente (MMA). 
Agregou-se a esse arcabouço a definição de um conjunto de indicadores e descritores, tendo como base conceitual e metodológica o documento A Handbook for Measuring the Progress and Outcomes of Integrated Coastal and Ocean Management, publicado pela Comissão Oceanográfica Intergovernamental (COI) da UNESCO (IOC, 2006). Deve-se ressaltar que a proposição metodológica constante no referido documento diz respeito, especificamente, à avaliação do processo de Gerenciamento Costeiro Integrado, sendo, portanto, adaptada e modificada visando aos objetivos da presente pesquisa.

O fluxograma da Figura 2 ilustra o processo de construção da metodologia aplicada na presente avaliação, a qual será descrita a seguir.

\subsection{Planejamento}

Foram realizadas duas reuniões de planejamento entre as equipes das Universidades envolvi- das nessa avaliação com os técnicos do Ministério do Meio Ambiente, especificamente da Gerência Costeira e da Gerência de Zoneamento Ecológico-Econômico, com o objetivo de definir seus escopos conceitual e metodológico, os quais serão explicitados a seguir.

\subsection{Análise documental}

A pesquisa documental aqui realizada é análoga a um levantamento bibliográfico tradicional, porém, com notável destaque para a busca de materiais que não foram elaborados com fins puramente científicos e publicados em revistas específicas. São exemplos: documentos oficiais, relatórios técnicos, material cartográfico e jurídico (Marconi \& Lakatos, 1985).

Todo o material levantado e analisado foi sistematizado em uma plataforma de armazenamento de dados on-line, na qual os dados podem ser acessados publicamente. Os documentos foram classificados

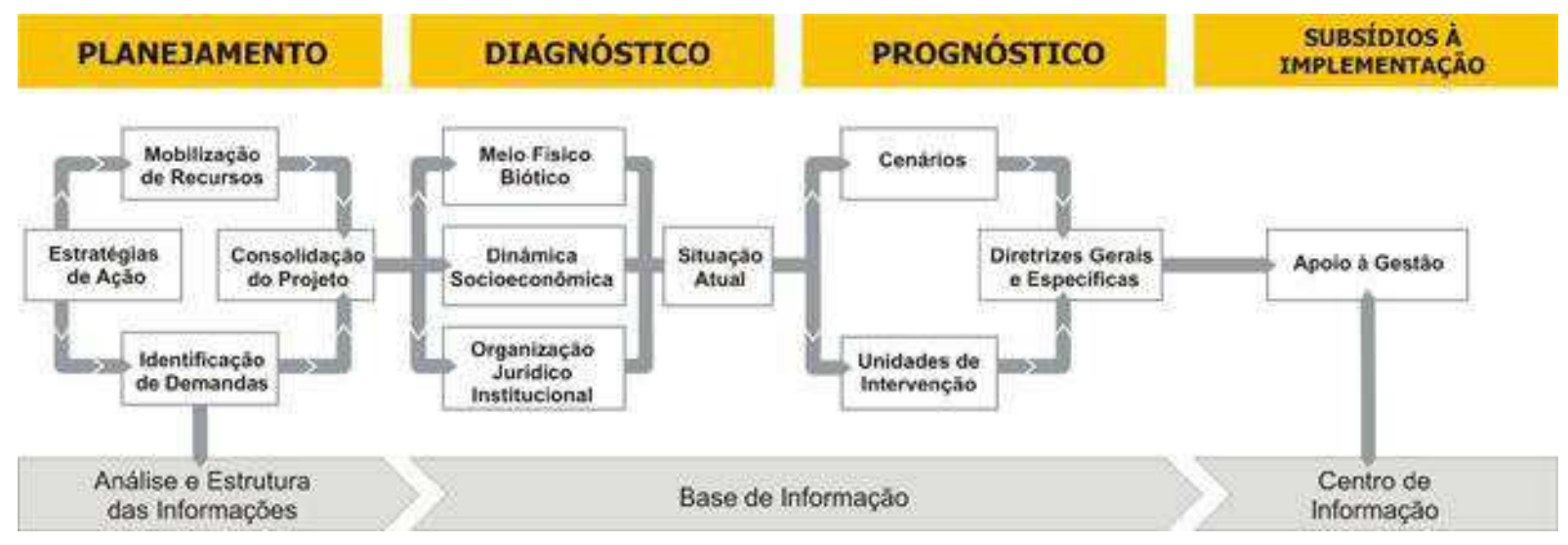

FIGURA 1 - Fluxograma de fases e processos para a elaboração do Zoneamento Ecológico-Econômico.

FONTE: Adaptado de MMA (2006). Este fluxograma serviu como base de orientação para o desenvolvimento proposto na presente análise. 


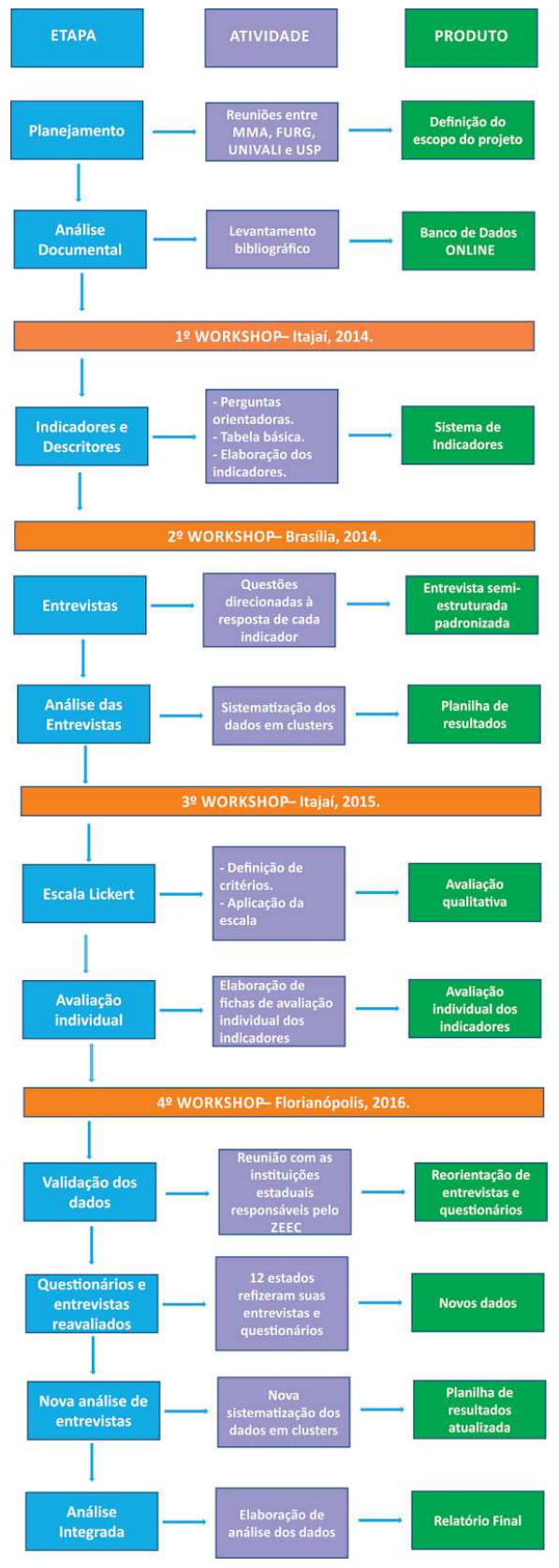

FIGURA 2 - Fluxograma da estratégia metodológica desenvolvida para avaliação dos Zoneamentos Ecológico-Econômicos costeiros (ZEEC) do Brasil. em: publicações oriundas da academia, avaliações nacionais já realizadas, banco de entrevistas, diretrizes metodológicas, informações por estados e legislação.

\subsection{O sistema de indicadores}

A principal etapa da metodologia desenvolvida para avaliação dos ZEECs no Brasil consistiu no desenvolvimento de um sistema de 35 indicadores que pudessem, de forma expedita, representar o estado da arte de tais instrumentos de gestão territorial.

Como base conceitual para a construção deste sistema, partiu-se de referências utilizadas na literatura científica específica (Kerr, 1994; Coltrinari \& McCall, 1995; Mitchell et al., 1995; Mannis, 1996; Berger, 1997; Baker, 1998; Jannuzzi, 2005; Rechden Filho, 2005; Oliveira \& Souza, 2007; Tavares et al., 2007; Magalhães Júnior, 2011) e, com maior destaque, IOC (2006). As características básicas dos indicadores adotados neste estudo estão descritas na Tabela 1.

Deve-se estabelecer uma redução necessária à compreensão dos resultados aqui apresentados: embora existam diferenças na definição de indicadores e descritores, a presente análise irá padronizar a terminologia "indicadores" para todos os 35 conjuntos de critérios analisados.

A construção do sistema de indicadores consistiu em três etapas básicas: a) formulação de uma lista de perguntas referentes ao objeto da avaliação; b) construção de uma tabela básica, seguindo os critérios da Tabela 1; c) elaboração dos indicadores.

A formulação da lista de perguntas referentes ao objeto da avaliação partiu da concepção do que 
se buscava com as mesmas, chegando a três grupos de perguntas:

- Perguntas de natureza descritiva, as quais buscam descrever os processos envolvidos na construção do ZEEC;

- Perguntas de natureza explicativa, as quais buscam explicar os processos e fenômenos envolvidos na construção do ZEEC;

- Perguntas de natureza interpretativa, as quais buscam interpretar como os fenômenos ocorrem na elaboração e na implementação do ZEEC.

Cabe destacar que, nesse primeiro momento, não houve a preocupação se as perguntas eram "possíveis de serem respondidas" ou, ainda, se havia conexão clara entre as mesmas. $\mathrm{O}$ exercício em questão contou com um brainstorming por parte da equipe do projeto, amparada pelo referencial teórico e legal identificado. Além disso, aproveitaram-se reuniões e encontros com os coordenadores estaduais do GERCO para ampliar e qualificar esse conjunto de perguntas, uma vez que são relevantes atores sociais do processo em análise. Outra característica é que tais perguntas têm um caráter meramente orientador, não se configurando, necessariamente, em questionamentos feitos durante o processo de obtenção dos dados que alimentaram o sistema de indicadores.

Como consequência, a Tabela 2 foi elaborada para construção dos indicadores, partindo do estabelecimento de um conjunto de metadados responsáveis por caracterizar cada um dos indicadores. Entre os elementos importantes foram considerados: contexto, objetivo, relação com outros indicadores, indicadores suplementares, definições e metodologia, área geográfica, unidade de medida, afinidade com o ZEE, metas a alcançar ${ }^{2}$, periodicidade, fontes de dados, limitações do indicador e referências.

Com base nessa tabela, a construção dos indicadores e descritores foi feita em oficinas e workshops realizados ao longo do processo de avaliação ${ }^{3}$, nos quais foram identificados, no conjunto

TABELA 1 - Síntese de características desejáveis ao que nortearam a elaboração dos indicadores sobre Zoneamento Ecológico-Econômico Costeiro no Brasil.

\begin{tabular}{ll}
\hline Característica & Descrição \\
\hline Facilmente mensuráveis & $\begin{array}{l}\text { Considerar a escala de tempo necessária para dar suporte ao gerenciamento, usando instrumentos } \\
\text { existentes, programas de monitoramento e ferramentas analíticas disponíveis. }\end{array}$ \\
\hline Concretos & $\begin{array}{l}\text { Indicadores que são observáveis e mensuráveis de forma direta são desejáveis porque eles são mais } \\
\text { facilmente interpretáveis e são aceitos por diversos grupos de tomadores de decisão. }\end{array}$ \\
\hline Interpretáveis & $\begin{array}{l}\text { Indicadores devem refletir propriedades que interessem aos tomadores de decisão; os seus significa- } \\
\text { dos devem ser compreendidos pela maior parte destes. }\end{array}$ \\
\hline Sensíveis & Indicadores devem ser sensíveis a mudanças nas propriedades que estão sendo monitoradas. \\
\hline Responsivos & $\begin{array}{l}\text { Indicadores devem ser capazes de medir os efeitos das ações do gerenciamento para que possam } \\
\text { fornecer um feedback (respostas) confiável com relação às consequências destas ações. }\end{array}$ \\
\hline Específicos & Indicadores devem responder às propriedades que eles pretendem medir e não a outros fatores. \\
\hline $\begin{array}{l}\text { Fundados em teorias cien- } \\
\text { tíficas }\end{array}$ & $\begin{array}{l}\text { Indicadores devem ser fundamentados em teorias científicas de boa aceitação, ao invés de outras } \\
\text { definidas inadequadamente ou ligadas a teorias pobremente validadas. }\end{array}$ \\
\hline Rentáveis & $\begin{array}{l}\text { Indicadores devem ser rentáveis, uma vez que os recursos para o monitoramento são, geralmente, } \\
\text { limitados. }\end{array}$ \\
\hline
\end{tabular}


de perguntas, aqueles que tinham encadeamento lógico a fim de buscar respostas a determinadas questões. Após essa identificação, as sequências de perguntas foram adaptadas à Tabela 2 , formando, ao final desta etapa, um conjunto de 35 indicadores.

A concepção dos indicadores seguiu uma sequência lógica que buscou compatibilizá-los às fases e aos processos para a elaboração do Zoneamento Ecológico-Econômico (MMA, 2006), como pode ser observado na Tabela 3.

\subsection{As entrevistas semiestruturadas}

Para a consecução das metas da presente avaliação, foram realizadas entrevistas semiestrutura- das com atores-chaves que atuam na governança do planejamento territorial nos estados. Cabe destacar que os entrevistados foram selecionados tendo em vista a competência institucional do órgão em que atuam, associando-a à atribuição do entrevistado na instituição. Ou seja, optou-se por atores que atuam diretamente na temática, em funções que articulam o processo decisório à atuação técnica. Também foram entrevistados atores que possuem domínio sobre o processo histórico do ZEE, ainda que hoje não estivessem atuando diretamente na pasta. Para selecionar os atores estratégicos, além da análise institucional pretérita, foi utilizada a técnica "bola de neve", em que um ator-chave indica outros, e assim por diante (Biernarcki \& Waldorf, 1981).

TABELA 2 - Tabela básica, a partir da qual foram estabelecidos os indicadores utilizados na análise sobre Zoneamento Ecológico-Econômico Costeiro no Brasil.

\begin{tabular}{|c|c|}
\hline Nome & Indicador / Descritor \\
\hline Descrição breve & Explicação sucinta do indicador e do contexto. \\
\hline Finalidade / Relevância & Por que deve ser monitorado? Como está relacionado com os processos analisados? \\
\hline Natureza do indicador & $\begin{array}{l}\text { Técnico: aqueles que fazem menção a informações de caráter material, operacional, etc. } \\
\text { Governança: aqueles que fazem menção a informações de caráter institucional, político, } \\
\text { de planejamento, etc. } \\
\text { Em caso de escala estadual, enquadra-se nos macrogrupos de indicadores? } \\
\text { - Planejamento } \\
\text { - Diagnóstico } \\
\text { - Prognóstico } \\
\text { - Subsídio à implementação. }\end{array}$ \\
\hline Esfera governamental & Em que nível deve se dar o monitoramento? Estadual ou nacional? \\
\hline Método de medição & $\begin{array}{l}\text { Quantitativo ou qualitativo? Qual a unidade mensurável (\%, número de pessoas, recur- } \\
\text { sos financeiros, existência ou ausência, etc.)? }\end{array}$ \\
\hline Frequência de medição & Periodicidade do monitoramento. \\
\hline Limitações de monitoramento e dados & Dificuldades em reunir dados e usar os resultados. \\
\hline Referências essenciais & Análise de relatórios técnicos, bibliografias, entrevistas e banco de dados. \\
\hline Fontes de informação & Instituições públicas e privadas, organizações não governamentais e Universidades. \\
\hline Observações & Outros processos e produtos relacionados ao assunto (instrumentos correlatos). \\
\hline
\end{tabular}


Para todas as entrevistas foram estabelecidos, preteritamente, roteiros semiestruturados (questionários) com questões específicas, de acordo com os indicadores estabelecidos previamente. Posteriormente à etapa de execução das entrevistas, foi realizada sua transcrição, seguida de uma categorização analítica e criteriosa. Ressalta-se que tais categorias de análise, por sua vez, foram relacionadas à organização estrutural do presente trabalho, facilitando, assim, a separação e o uso das informações das entrevistas.

A análise dos resultados fez uso das técnicas de triangulação da informação e de coleta de dados, ou seja, foi utilizada mais de uma fonte para análise e compreensão do fenômeno, de forma a validar as informações qualitativas. Tais fontes derivam tanto das entrevistas quanto da análise documental realizada, a fim de observar a compatibilidade das informações (Triviños, 1987).

\subsection{Escala Lickert}

Como forma de sistematização das informações obtidas nessa avaliação, buscou-se uma representação "semiquantitativa" gráfica por meio da aplicação da escala Lickert, caracterizada como uma escala de resposta psicométrica utilizada em pesquisas de opinião de clientes, no caso da iniciativa privada, ou em atores sociais, como foi o caso desta avaliação. Sendo uma das principais KPI's (Key Performance Indicators) de pesquisas do mundo, a escala é um dos indicadores mais antigos e tradicionais para fins de atendimento de determinadas condições em situações específicas.

TABELA 3 - Compartimentação lógica dos indicadores nas fases do Zoneamento Ecológico-Econômico Costeiro no Brasil, segundo o MMA (2006). Os indicadores estão descritos na Figura 4.

\begin{tabular}{ccc}
\hline Fase & Categorias & Indicadores \\
\hline \multirow{2}{*}{ Planejamento } & Arcabouço normativo e institucional & 1 a 8 \\
\cline { 2 - 3 } Diagnóstico e Prognóstico & Abrangência geográfica e escalas & 9 a 12 \\
\hline & $\begin{array}{c}\text { Articulação interinstitucional e participa- } \\
\text { ção social }\end{array}$ & 13 a 18 \\
\cline { 2 - 3 } & Aspectos metodológicos & 19 a 24 \\
\hline \multirow{2}{*}{ Implementação e Avaliação } & Aprovação & 25 a 27 \\
\cline { 2 - 3 } & Base de dados e acesso à informação & 28 a 30 \\
\hline & Capacitação, monitoramento e avaliação & 31 a 33 \\
\cline { 2 - 3 } & seus instrumentos & 34 a 35 \\
\hline
\end{tabular}

\footnotetext{
${ }^{2}$ Aqui considerados como valores de referência a serem atingidos pelos indicadores enquanto ferramenta de gestão pública.

${ }^{3}$ Foram realizadas duas reuniões de planejamento na sede do Ministério do Meio Ambiente (MMA), em Brasília, mais 4 workshops, sendo dois deles na sede da Univali, em Itajaí, outro na sede do MMA e o workshop final de validação dos resultados na sede do Instituto Estadual do Ambiente (INEA), no Rio de Janeiro.
} 
Procurou-se aqui classificar os dados obtidos na aplicação do sistema de indicadores em três categorias: 1 = Não atende; = Atende parcialmente; $3=$ Atende.

A leitura dos resultados dessa escala deve ser feita com algumas ressalvas:

- Os critérios para definição das três categorias possuem certo grau de subjetividade, uma vez que foram concebidos em função de um "ótimo" teórico em relação a cada indicador;

- Não se trata, em momento nenhum, da elaboração de um ranking dos estados enquanto suas responsabilidades e atribuições perante o ZEEC;

- Os valores numéricos aqui obtidos são apenas formas de representação da situação analisada nos indicadores. Por serem valores ordinais, não há uma relação direta algébrica entre estes valores. Por exemplo, se o somatório de determinado indicador foi ' 16 ' e outro '32', não significa necessariamente que os critérios analisados pelo segundo indicador apresentam o dobro da eficiência ou de qualidade em relação ao primeiro.

\subsection{Fichas de avaliação individual}

Como forma de proceder à avaliação dos indicadores propostos, criou-se uma ficha de avaliação individual, que foi aplicada para cada um dos 35 indicadores propostos.

Tal ficha foi composta por: a) representação gráfica dos resultados obtidos para determinado indicador; b) descrição do resultado (meramente descritivo, como uma leitura simples do gráfico); c) análise específica dos resultados; d) análise da aplicação do indicador (visando a futuros aperfeiçoamentos); e) enquadramento do resultado em uma escala Lickert, onde o resultado do indicador foi classificado como "atende", "atende parcialmente" e "não atende" determinado critério. Essa classificação foi feita por estado da Federação.

Cabe destaque o fato de que essa classificação na escala Lickert buscou identificar se o aspecto analisado pelo indicador poderia ser classificado nas categorias supracitadas ("atende", "atende parcialmente" ou "não atende"), não se tratando de avaliar o indicador em si, e sim avaliar o aspecto do ZEEC ao qual o mesmo diz respeito.

\subsection{Workshop de validação}

Depois de cumpridas todas as etapas de obtenção, sistematização e análise dos resultados, foi realizado um workshop de validação dos mesmos. Tal evento foi organizado em parceria com o Ministério do Meio Ambiente na cidade do Rio de Janeiro, no auditório do Instituto Estadual do Ambiente (INEA), no mês de novembro de 2016. Esse evento contou com a participação de 15 estados costeiros (representados por técnicos diretamente ligados à instituição responsável pelo ZEEC), técnicos da Gerência de Zoneamento Ecológico-Econômico e da Gerência Costeira do MMA, bem como por pesquisadores das três Universidades envolvidas.

O objetivo central de tal evento foi aproximar os gestores dos resultados obtidos, bem como da análise realizada, visando complementar informações e/ou elucidar aspectos avaliados. Tal foco mostrou-se muito pertinente, uma vez que, após se apropriarem do arcabouço total da pesquisa, 12 dos 16 estados que compõem o universo amostral 
desta avaliação solicitaram revisar as informações que haviam sido cedidas. Embora tal situação tenha acarretado na reestruturação de praticamente toda a análise, o reenvio destas informações permitiu obter um cenário muito mais realístico do contexto do ZEEC no país.

\section{Resultados e discussão}

A estratégia metodológica descrita anteriormente foi aplicada em 16 dos 17 estados costeiros do Brasil, sendo que apenas o estado do Piauí não fez parte do universo de análise, uma vez não ter sido possível o estabelecimento dos contatos prévios necessários.

Como trata-se de metodologia aplicada para a identificação da situação de elaboração e de implementação de um instrumento da política de gerenciamento costeiro nacional, os resultados serão discutidos no âmbito não apenas metodológico, mas também com o viés do resultado obtido com sua aplicação.

Pode-se considerar que o Zoneamento Ecológico-Econômico tem sido o instrumento do Programa Nacional de Gerenciamento Costeiro mais difundido no Brasil; no entanto, existe um imenso desafio para sua implementação e avaliação.

Estabelecer as bases de um zoneamento ecológico e econômico em uma determinada conjuntura geográfica equivale a realizar um estudo para determinar a vocação de todos os subespaços que compõem certo território e efetuar o levantamento de suas potencialidades econômicas, sob um critério basicamente ecodesenvolvimentista (Ab'Saber, 1989).

No Brasil, o grande desafio deste momento está em resgatar o conhecimento do passado e da realidade atual e, desta forma, potencializar as riquezas inerentes do território costeiro sob os pontos de vista ambiental, econômico, social e cultural. Buscar estabelecer espaços adequados para os diversos setores econômicos exige, antes de tudo, responsabilidade para compatibilizar melhoria da qualidade de vida para a população e conservação dos espaços naturais.

Apesar de ser um instrumento de planejamento, o Zoneamento Ecológico-Econômico cumpre esta função, pois traz em seu escopo uma medida lógica para auxiliar na tomada de decisão baseada em premissas de cunhos técnico, legal, institucional e administrativo.

Interessante destacar que o ZEEC também é um instrumento que se integra aos mais diferentes mecanismos da política ambiental (i.e., Licenciamento Ambiental), tanto nas escalas nacional e regional quanto na local. Neste sentido, na consecução do instrumento fica evidente que o ZEEC se integra ao processo de gestão por meio de relações institucionais, legais e administrativas específicas, mas complexas, pois exige um amplo processo de participação, além de mediação política.

Como parte da compreensão do panorama atual de elaboração e de implementação do ZEEC no país, é apresentada uma síntese da situação em cada estado costeiro da Federação. Tal síntese preliminar, que não expressa a análise conjuntural do processo do ZEEC no Brasil, visto que somente é possível fazê-lo sob o prisma da análise integrada de todos os dados obtidos, pode ser observada na Tabela 4.

Do ponto de vista qualitativo, buscou-se agrupar os estados em conjuntos que viessem a expressar estágios de maturidade em relação à governança estabelecida para a elaboração e a implementação do ZEEC nas suas respectivas zonas costeiras. 
Para a definição dos estágios de maturidade, foram considerados os seguintes critérios para cada estado: experiência institucional em relação aos processos e fases do ZEEC, existência de agenda política institucionalizada de Gerenciamento Costeiro e avanço do processo do ZEEC nos setores costeiros em suas diferentes fases.

A Tabela 5 descreve os estágios de maturidade do processo em si, bem como aponta os parâmetros de aproximação utilizados nesta classificação, representados visualmente na Figura 3.

Percebe-se existir relação direta entre a situação institucional do Gerenciamento Costeiro no estado com o grau de maturidade do processo do ZEEC, embora essa relação seja de difícil mensuração, estando expressa aqui apenas de forma qualitativa. Tal classificação buscou ancorar um contexto mais amplo do que o atual, uma vez que a priorização das agendas de gerenciamento costeiro varia conforme as conjunturas políticas e econômicas dos estados. Como exemplo, cita-se o caso do Rio Grande do Sul, que desde 1988 teve o GERCO institucionalizado e atuante no âmbito da Fundação de Proteção Ambiental (FEPAM), mas que desde 2016 teve sua estrutura desarticulada, com o reposicionamento das agendas em outros setores.

Cabe ressaltar que não há, necessariamente, relação direta entre o nível de maturidade (Tabela 5) com a eficiência prática do instrumento no planejamento territorial e na tomada de decisão, embora seja o mesmo um forte indicativo de maior ou menor grau de sucesso do ZEEC.

A Figura 4 apresenta os resultados obtidos com a aplicação dos 35 indicadores agrupados na escala Lickert, considerando a ordem lógica explicitada na Tabela 3. As cores indicam as seguintes situações: Branco $=$ valor zero (não se aplica); Vermelho = valor
1 (não atende ao indicador); Amarelo = valor 2 (atende parcialmente); Verde $=$ valor 3 (atende ao indicador).

O conjunto de classificações feito por meio da Escala Lickert permite uma visão completa e integrada dos avanços do ZEEC para o conjunto dos estados. Mesmo que não aponte, numa primeira vista, nenhum claro padrão, a classificação indica de forma direta aqueles aspectos (indicadores) atendidos, em algum nível, pela totalidade ou pela maioria dos estados. Da mesma forma, aponta aqueles indicadores raramente ou nunca (indicador 35 ) atendidos pelo conjunto dos estados.

Embora desprovidos de tratamento estatístico de significância, chama a atenção que a mediana das somas dos indicadores cai de 35 para 29 desde a fase de Planejamento (indicadores 1-12) para a fase de Diagnóstico (indicadores 13-24) e 24 para a fase de Implementação (indicadores 24-35). Tal tendência indica uma crescente dificuldade em cumprir adequadamente os elementos e os procedimentos que compõem o ZEEC desde a sua concepção (Planejamento) até a sua completa realização (Implementação e Avaliação).

A partir da análise individualizada dos indicadores, pode-se traçar um interessante panorama da situação de elaboração e de implementação do Zoneamento Ecológico-Econômico Costeiro (ZEEC) no Brasil. Tal panorama aponta, se não para um cenário favorável, para uma situação de consolidação e de maturidade do instrumento de gestão, embora não de forma homogênea, ao longo da costa brasileira. Além disso, o cenário diagnosticado não indica, necessariamente, uma melhor condição socioambiental em determinado território, efeito certamente desejado em tal contexto.

Em uma ótica meramente quantitativa, vale salientar a percepção de significativos avanços no processo. Em 1997, apenas um estado apresentava o Zoneamento Ecológico-Econômico Costeiro. 
Em avaliação feita durante o workshop nacional "Diretrizes Técnicas, Políticas e Institucionais para o Gerenciamento Costeiro", realizado na cidade de Maceió, AL, em 2006, 59\% dos estados possuíam o ZEEC elaborado, mesmo que em algumas frações de suas Zonas Costeiras. Destes, quatro estados (24\%) possuíam o zoneamento instituído por norma legal.

A atualização destes números, realizada na presente avaliação, indica que apenas os estados de Sergipe, Alagoas, Maranhão e Pará não possuem o

TABELA 4 - Síntese da situação atual da elaboração e implementação do Zoneamento Ecológico-Econômico Costeiro no Brasil (ZEEC), por estados.

\begin{tabular}{|c|c|}
\hline \multicolumn{2}{|r|}{ Panorama atual de elaboração e implementação do ZEEC nos estados } \\
\hline Estado & Resumo da situação do ZEEC \\
\hline RS & $\begin{array}{l}\text { Um dos pioneiros no processo de ZEEC no país, dando início aos trabalhos referentes ao ZEE do Litoral Norte ainda } \\
\text { em 1988. Este ZEEC é vigente, embora não tenha respaldo normativo específico. Em 2000, o mesmo foi publicado } \\
\text { e amplamente divulgado. Atualmente está em processo de elaboração do ZEE do Estado, o qual já tem sua proposta } \\
\text { técnica finalizada e o diagnóstico em fase de execução. } \\
\text { Não possui nenhuma iniciativa de ZEE marinho. }\end{array}$ \\
\hline $\mathrm{SC}$ & Possui o ZEEC em fase de implementação para os seus cinco setores costeiros. \\
\hline PR & $\begin{array}{l}\text { Existem dois zoneamentos propostos. Em } 2006 \text { foi lançada, pela Secretaria Estadual de Meio Ambiente, a publicação } \\
\text { Paraná Mar e Costa, com uma proposta de zoneamento costeiro e marinho. Este zoneamento não foi instituído formal- } \\
\text { mente e, a partir de 2011, foi elaborado o ZEE PR - Litoral, o qual foi institucionalizado e normatizado por meio do } \\
\text { Decreto 4.996/2016. }\end{array}$ \\
\hline SP & $\begin{array}{l}\text { Estado com a situação de ZEEC mais avançada. Discute experiências de zoneamento ambiental desde o final da déca- } \\
\text { da de 1970. O ZEEC do Litoral Norte foi regulamentado pelo Decreto Estadual no } 49.215 / 04 \text { e encontra-se vigente. Já } \\
\text { o ZEEC da Baixada Santista foi regulamentado pelo Decreto Estadual no } 58.996 \text {, de 2013. Já nos demais setores (Vale } \\
\text { da Ribeira e Cananéia-Iguape) o processo encontra-se em fases distintas: planejamento/diagnóstico e diagnóstico/prog- } \\
\text { nóstico, respectivamente. }\end{array}$ \\
\hline RJ & $\begin{array}{l}\text { Atualmente desenvolve o ZEEC para o setor costeiro da Ilha Grande, com apoio da FAO via Projeto Gestão Integrada } \\
\text { do Ecossistema da Baía da Ilha Grande (Projeto BIG). Encontra-se em fase de prognóstico. }\end{array}$ \\
\hline ES & $\begin{array}{l}\text { O estado possui ZEE elaborado com base no ZEE de Minas Gerais, feito pela Universidade Federal de Lavras. Ten- } \\
\text { tou-se aplicar a mesma metodologia para a zona costeira, não obtendo resultados positivos. Buscou-se desenvolver } \\
\text { metodologia própria para a zona costeira e marinha. O processo não foi concluído, parando na fase de diagnóstico. }\end{array}$ \\
\hline BA & $\begin{array}{l}\text { Possui ZEE estadual que abrange a zona costeira. Teve sua definição territorial com base em territórios de identidade } \\
\text { da Bahia. Embora a zona costeira esteja representada no ZEE, não se trata especificamente de um ZEEC. Não há } \\
\text { zoneamento marinho. }\end{array}$ \\
\hline SE & $\begin{array}{l}\text { Não tem o Gerenciamento Costeiro institucionalizado e reconhecido como agenda política. Não existem iniciativas } \\
\text { para a elaboração do ZEEC. }\end{array}$ \\
\hline AL & $\begin{array}{l}\text { Vem realizando estudos prévios que poderão subsidiar um futuro ZEEC. Atualmente o PEGC encontra-se em discus- } \\
\text { são. }\end{array}$ \\
\hline $\mathrm{PE}$ & $\begin{array}{l}\text { Constitui-se em um dos estados com estágio mais avançado de implementação do ZEEC, embora ainda de forma } \\
\text { parcial no território. As discussões acerca do ZEE Litoral Sul começaram ainda na década de } 1990 \text { e culminaram } \\
\text { com sua publicação no Decreto 21.972/99. Já o Litoral Norte tem seu ZEE publicado no Decreto 24.017/2002, com } \\
\text { alterações no Decreto 28.822/2006. Em 2010, a Política Estadual de Gerenciamento Costeiro-PEGC foi instituída pela } \\
\text { Lei } 14.258 / 2010 \text {. }\end{array}$ \\
\hline PB & $\begin{array}{l}\text { Possui ZEEC estabelecido para seus dois setores costeiros (Lei 7.507/2003). Também se enquadra nos estados pionei- } \\
\text { ros na elaboração do instrumento no Brasil. Não há zoneamento marinho. }\end{array}$ \\
\hline
\end{tabular}




\begin{tabular}{ll}
\hline RN & $\begin{array}{l}\text { Possui o ZEE para o Litoral Oriental (Lei 7.871/00) e encontra-se em planejamento para a realização do ZEE Litoral } \\
\text { Norte. O estado possui Plano Estadual de Gerenciamento Costeiro desde 1996. Não há zoneamento marinho. }\end{array}$ \\
\hline CE & $\begin{array}{l}\text { Possui Plano Estadual de Gerenciamento Costeiro desde } 2006 \text { (Lei 13.796/06). Possui ZEEC para os seus quatro } \\
\text { setores costeiros. Não possui ZEE marinho. }\end{array}$ \\
\hline MA & $\begin{array}{l}\text { Possui um Zoneamento Ambiental estabelecido em } 2003 \text { voltado à atividade de Aquicultura, que abrange a zona cos- } \\
\text { teira do estado. Atualmente encontra-se em fase de pré-planejamento para a elaboração do ZEEC. }\end{array}$ \\
\hline & $\begin{array}{l}\text { Possui ZEE da Zona Leste e Calha Norte do estado, abrangendo parte da região costeira. Foi elaborado em 2010, pelo } \\
\text { PA }\end{array}$ \\
$\begin{array}{l}\text { Programa Pará Rural do governo do estado. Esse zoneamento não comtempla importantes especificidades da zona cos- } \\
\text { de pré-planejamento para a realização do ZEEC. }\end{array}$ \\
\hline AP & O ZEEC encontra-se em fase de prognóstico para o Setor Costeiro Atlântico. Não há ZEE marinho. \\
\hline
\end{tabular}

TABELA 5 - Classificação por estágios de maturidade dos estados em relação aos processos de elaboração e de implementação do Zoneamento Ecológico-Econômico Costeiro no Brasil.

\begin{tabular}{lll}
\hline Grupo & Parâmetros & Estados \\
\hline \multirow{3}{*}{ Maduro } & - Ampla experiência com ZEEC. & RS, SC, PR, SP, PE, PB, RN, \\
& - Agenda do GERCO institucionalizada e atuante. & CE \\
& - Pelo menos um setor costeiro com processo em implementação. & RJ, ES, BA, AP \\
Intermediário & - Agenda do GERCO institucionalizada ou atuante. & \\
& - Possui experiência com ZEE (costeiro ou não). & AL, MA, PA \\
& - Possui ZEE em fase de diagnóstico ou prognóstico em pelo menos um & \\
Incipiente & setor costeiro. & Apenas manifestações de interesse em elaborar o ZEEC (pré-planejamen- \\
& to). & - Agenda do GERCO não institucionalizada ou sem agenda própria. \\
\hline \multirow{2}{*}{ Inexistente } & - Possui algum tipo de zoneamento ambiental na ZC. & SE \\
\hline
\end{tabular}

Zoneamento Ecológico-Econômico em sua zona costeira, elevando o percentual de estados com ZEEC para mais de $75 \%$.

Aqui cabe uma ressalva ao entendimento do processo: a generalização do conceito de zoneamento ambiental, a partir de sua inserção na Política Nacional do Meio Ambiente (Lei Federal $n^{\circ}$ 6.938/1981), aliada ao contexto histórico e político vigente à época, fez com que, ao longo do tempo, diversas iniciativas de zoneamentos fossem levadas a cabo pelos estados, sendo até hoje confundidos com o ZEEC.

Chama a atenção o fato de que em alguns estados o zoneamento foi feito de forma setorial, como no caso de zoneamentos focados no uso da carcinicultura no Maranhão, ou ainda o zoneamento territorial feito pelo Programa Pará Rural do governo do estado. Embora tais zoneamentos englobem parte das zonas costeiras de seus estados, os mesmos não podem ser considerados ZEEC como proposto 
no PNGC, pois se distanciam do desejado enfoque de integração multissetorial para o planejamento e a gestão da zona costeira.

Do ponto de vista metodológico, a execução das etapas descritas na Figura 2 mostraram-se eficientes, uma vez que permitiram aportar a discussão aqui presente. Mas, alguns pontos merecem maior atenção visando ao aperfeiçoamento do método.

$\mathrm{O}$ primeiro diz respeito à inerente subjetividade dos resultados obtidos via entrevistas.
Mesmo que os atores tenham sido criteriosamente identificados, o envolvimento dos mesmos (alguns durante décadas) com a temática junto às suas instituições pode gerar uma interpretação pouco crítica da situação. Tal situação foi amenizada por meio do cruzamento entre as informações obtidas em entrevistas com os dados documentais analisados.

Outro ponto crucial é a transposição do que se deseja obter com os indicadores para as entrevistas semiestruturadas, as quais por vezes não refletiram

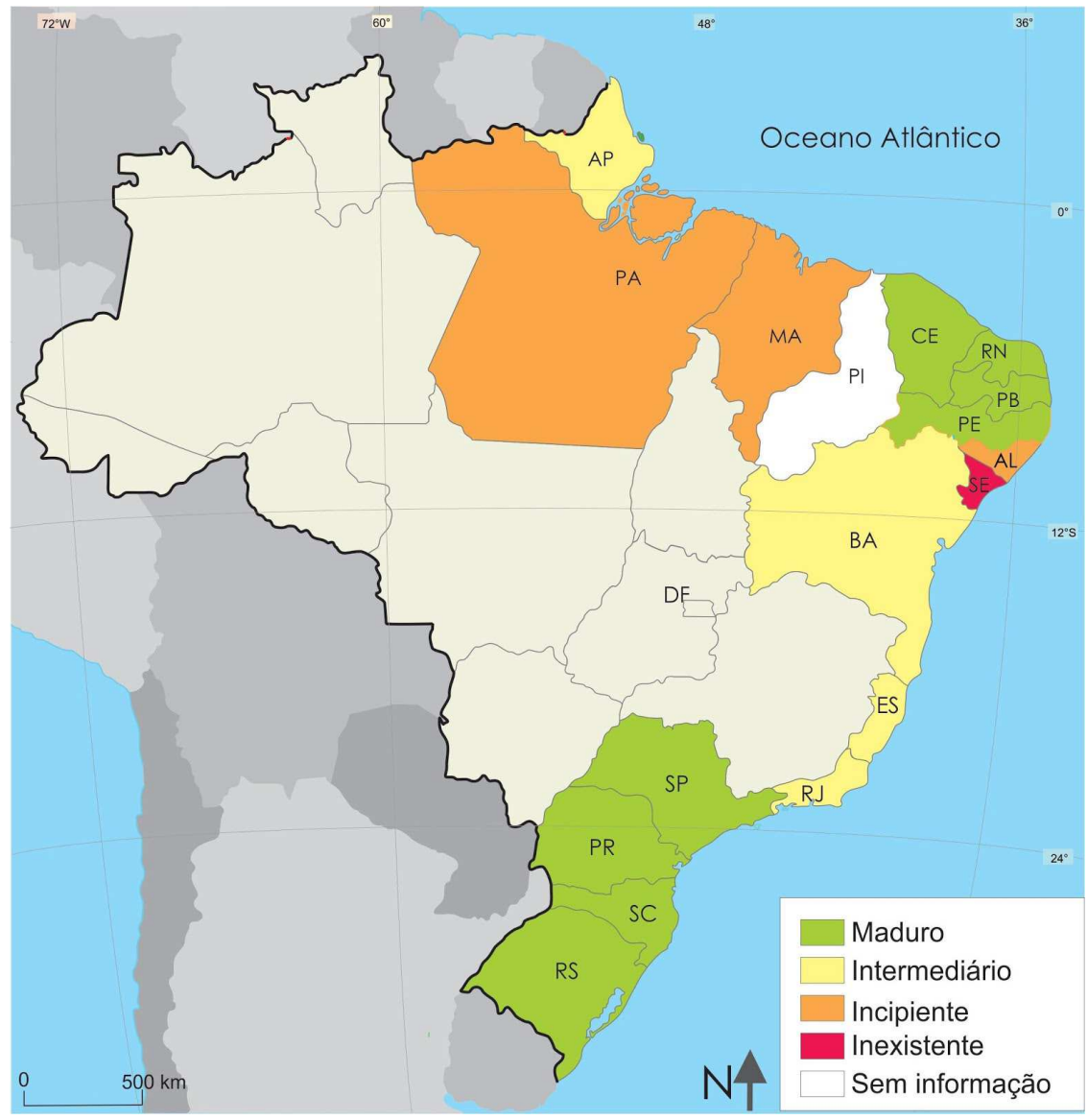

FIGURA 3 - Representação visual da classificação por estágios de maturidade do processo de elaboração e implementação do Zoneamento Ecológico-Econômico Costeiro no Brasil. 
a necessidade do entrevistador. Um bom exemplo é o indicador 18, "Metodologias para elaboração do ZEEC". Este indicador busca identificar se a metodologia utilizada para a elaboração do ZEEC seguiu as diretrizes básicas do MMA ou se foi elaborada metodologia própria.

Houve discrepância entre os entrevistados em relação à abrangência daquilo que se definiu como “metodologia do MMA”. Tal confusão é parte do próprio instrumental metodológico disponível no país. Como todos os estados fizeram adaptações em vista das múltiplas realidades locais, define-se que não há um método em si, e sim um conjunto de "bases" metodológicas, fazendo com que as respostas nos diferentes estados fossem de difícil correlação.

Uma avaliação da aplicação de cada indicador pode ser observada na tabela em anexo.

\section{Indicador}

Base normativa estadual do ZEEC

Natureza da instituição responsável pelo ZEEC

Prioridade institucional do ZEEC

Representatividade intersetorial no arranjo institucional

Equipe técnica diretamente envolvida no ZEEC

Dependência de recursos humanos externos por fase

Fonte dos recursos

Recorte(s) territorial(ais) do ZEEC

Percentual da linha de costa com ZEEC

Número de setores costeiros (território) com ZEEC

Escala Cartográfica

Articulação governamental no processo do ZEEC

Participação social formal

Composição da participação social formal

Mecanismos de participação social no processo do ZEEC

Número e distribuição territorial das Audiências Públicas

Consideração dos conflitos na elaboração do ZEEC

Compatibilidade metodológica por fases

Metodologia para a faixa marinha do ZEEC

Cartografia Temática

Natureza dos dados para elaboração do ZEEC

Critério(s)-chave(s) na delimitação das zonas-tipo

Compatibilização com zoneamentos setoriais

Setores costeiros com ZEEC instituído por ato normativo

Fase em que se encontra o ZEEC

Nivel de elaboração do ZEE na faixa marinha da ZC

Produtos gerados pelo ZEEC

Clareza dos produtos gerados pelo ZEEC

Acesso à informação

Diretrizes, plano de ação e metas do ZEEC

Consideração do ZEEC nas políticas setoriais do estado

Consideração ZEEC nas políticas territoriais/ambientais

Utilização do ZEEC no licenciamento ambiental

Capacitação para o ZEEC

Monitoramento e avaliação de metas e diretrizes

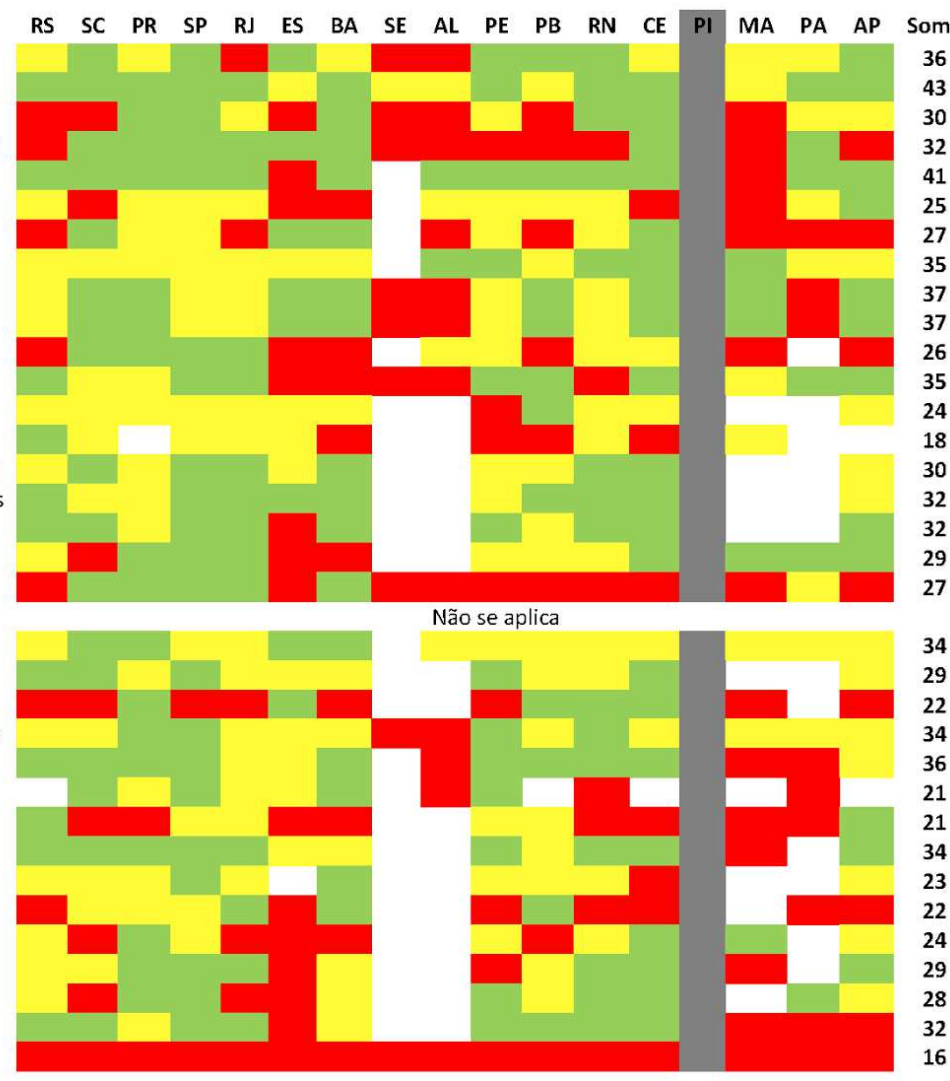

FIGURA 4 - Aplicação das três categorias da escala Lickert para os 35 indicadores utilizados na análise do Zoneamento Ecológico-Econômico Costeiro no Brasil, considerando os estados costeiros de sul (à esquerda) para norte (à direita). 


\section{Considerações finais}

Embora o foco do presente artigo seja a aplicação do método desenvolvido para a avaliação da situação do ZEEC no país, algumas considerações devem ser feitas sobre o instrumento em si, uma vez ser o objeto de sua elaboração.

O Sistema de Gerenciamento Costeiro no país completará 30 anos em 2018, configurando-se como uma política profundamente arraigada no âmbito da gestão ambiental e territorial, mesmo que essa posição não represente, necessariamente, efetividade nas ações implementadas no período.

Tal conjuntura adita características muito peculiares ao ZEEC, principalmente quando considerados os contextos históricos e políticos que perpassam estes quase 30 anos de sua elaboração e sua implementação.

O início dos esforços de zoneamento costeiro no Brasil ocorreu no contexto de um conjunto de pressões ao ambiente litorâneo em função, principalmente, do desenvolvimento econômico sem uma base territorial ordenada, bem como de compromissos internacionais assumidos pelo Brasil na Conferência das Nações Unidas sobre o Meio Ambiente e o Desenvolvimento (Eco-92).

De fato, os 17 estados costeiros apresentam diferentes contextos históricos e motivações que culminaram na elaboração e na implementação do ZEEC nos mais variados estágios, conforme demonstrado na presente análise. Pode-se inferir que a necessidade de conhecimento das características ambientais e socioeconômicas de cada estado e a premência de conciliação das diversas visões entre os diferentes níveis de governo acerca da ocupação e do uso do território costeiro foram preponderantes para que se atingisse o estágio atual no país. Além disso, cabe destaque também o papel do atendimento prestado pelo ZEEC ao cumprimento de especificidades legais, como, por exemplo, a Lei $n^{\circ}$ 12.651/2012 ("novo" Código Florestal).

Em um primeiro momento, a implantação da agenda do ZEEC nos estados costeiros contribuiu para a inserção da temática ambiental, em diferentes graus, na dinâmica da gestão do território, com marcada ênfase à preservação e à conservação de ecossistemas. Além disso, a implementação desta agenda propiciou aproximação entre setores de Universidades e poder público, reforçando as conexões tão desejadas entre a ciência e a sociedade. Tal aproximação foi essencial ao desenvolvimento de conjuntos de dados sistematizados e espacializados que compuseram durante algum tempo a principal base de diagnósticos temáticos disponíveis.

Dentre as principais valências da existência do ZEEC no âmbito das políticas públicas de gestão do território, podem-se destacar as seguintes:

- Articulação entre diversos setores da sociedade, uma vez ser o ZEEC um instrumento de âmago territorial em detrimento da visão meramente setorial;

- Geração de produtos técnicos para a sociedade;

- Orientação, ainda que de forma pouco incisiva, na elaboração dos planos plurianuais e das leis orçamentárias anuais dos estados;

- Possibilidade de integração com políticas de gestão territorial continental (Planos de Bacias Hidrográficas) e oceânica (Planejamento Estratégico Marinho - PEM);

- Identificação e mitigação de conflitos entre o território e seus usos, bem como entre os setores da sociedade que demandam tais usos; 
- Possibilidade de participação efetiva da sociedade, por meio de mecanismos específicos;

- Aproximação entre as equipes técnicas de diferentes instituições e esferas públicas;

- Subsídios a processos de identificação, caracterização, delimitação e criação de unidades de conservação e de corredores de biodiversidade;

- Orientação em processos de licenciamento ambiental nos estados.

Por fim, considera-se que, em termos específicos do ZEEC, sua elaboração e sua implementação de forma condizente com seus objetivos pressupõem algumas especificidades, sem as quais o processo tende a ser mais intrincado, lento e, muitas vezes, oneroso:

1) Existência de base normativa que preveja a elaboração e a implementação do ZEEC;

2) Existência de Plano Estadual de Gerenciamento Costeiro, tendo como um de seus instrumentos o ZEEC;

3) Definição clara da instituição responsável pela agenda política do GERCO e, por consequência, do ZEEC;

4) Presença de ações específicas do ZEEC em seus planos plurianuais (PPA);

5) Estabelecimento de comissão (ou similar) formal específica para o ZEEC no estado;

6) Estruturação de equipe técnica envolvida permanentemente com a elaboração do ZEEC, independente de contratações externas (convênios, parcerias, etc.);

7) Inserção do ZEEC como uma prioridade institucional, buscando recursos externos ao órgão para a execução do mesmo;
8) Viabilização de participação social formal, organizada e efetiva, propiciando apropriação, validação e legitimidade ao processo por parte dos atores sociais envolvidos;

9) Instituição do produto final do ZEEC por ato normativo e não apenas como um instrumento de consulta técnica;

10) Estabelecimento de comunicação como um dos elementos mais importantes nos processos de construção e de implementação do ZEEC. Metodologias transparentes e disponibilidade de dados e produtos na internet desde o início tendem a robustecer o processo;

11) Compreensão de que o ZEEC, embora seja um instrumento "fim", é um complexo processo que envolve inter-relações entre comunidades, interesses e perspectivas. Dessa forma, o ZEEC não pode ser tratado meramente como um estudo técnico, onde sobreposições de camadas de dados, por mais detalhadas que sejam, propiciarão subsídios de aplicação direta no planejamento territorial estratégico.

Com base nesse entendimento, a análise aqui proposta pressupôs o desenvolvimento de método próprio, que apresentou-se como satisfatório no que tange à obtenção e à análise dos resultados.

Os resultados obtidos permitem inferir que o método aplicado permitiu aprofundar e diversificar as análises de ZEEC existentes no país, avaliando o processo de forma ampla e relacionada com as concepções metodológicas inerentes ao instrumento.

Como sugestão para aplicações futuras do método, sugere-se a revisão de determinados indicadores (Anexo 1), bem como a compatibilização da premência da consecução dos indicadores com as entrevistas semiestruturadas, as quais, por vezes, não refletiram a necessidade do entrevistador. 


\section{Referências}

Ab'Saber, A. Zoneamento ecológico e econômico da Amazônia. Questões de escala e método. Estudos Avançados, 3(5), 1989. doi: 10.1590/S0103-40141989000100002

Araújo, C. P.; Gattamorta, M. A.; Silva, S. B. O zoneamento ecológico econômico enquanto instrumento de planejamento ambiental que antecede o planejamento urbano. In: Anais do XIV Encontro Nacional da ANPUR, Rio de Janeiro, Brasil, 2011.

Asmus, M. L.; Kitzmann, D.; Laydner, C.; Tagliani, C. R. A Gestão Costeira no Brasil: Instrumentos, fragilidades e potencialidades. Gerenciamento Costeiro Integrado, 4, 52-57, 2006.

Baker, D. S. Uma contribuição ao Sistema de Monitoramento de Biodiversidade em Unidades de Conservação Federais - SIMBIO. Indicadores Socioeconômicos e Indicadores de Desempenho Institucional. 28p. Relatório Técnico. Brasília, DF: IBAMA, 1998.

Bastos, F. H.; Silva, E. V. O Zoneamento Ecológico e Econômico como subsídio aos procedimentos de Licenciamento Ambiental na Zona Costeira do Estado do Ceará. In: Anais do VI Seminário Latino Americano de Geografia Física e II Seminário Ibero Americano de Geografia Física. Coimbra, Portugal. 2010.

Berger, A. R. Assessing rapid environmental change using geoindicators. Environmental Geology, 321, 36-44, 1997.

Biernarcki, P.; Waldorf, D. Snowball sampling-problems and techniques of chain referral sampling. Sociological Methods and Research, 10(2), 141-163, 1981.

Coccossis, H. Integrated coastal management and river basin management. Water, Air, \& Soil Pollution: Focus, 4, 411-419, 2004.

Coccossis, H.; Burt, T.; Weide, V. D. J. Conceptual framework and planning guidelines for integrated coastal area and river basin management. Split: PAP/RAC, UNEP/MAP/ PAP, Split, Priority Actions Programme: Mediterranean Action Plan. UNESCO, 1999.

Coltrinari, L.; McCall, G. Geo-Indicadores: Ciências da
Terra e Mudanças Ambientais. RDG, 9, 5-11, 1995.

Del Prette, M. E.; Matteo, K. C. Origens e possibilidades do Zoneamento Ecológico-Econômico no Brasil. In: Cadernos de Referência, Subsídios ao Debate. Programa ZEE, MMA, Secretaria de Políticas para o Desenvolvimento Sustentável. Brasília, Brasil, 2006.

Ferreira, V. J. R. P. Avaliação do zoneamento ecológico econômico no município do Rio de Janeiro como ferramenta para a gestão territorial integrada e desenvolvimento sustentável. 140 p. Rio de Janeiro, Dissertação (Mestrado) - Programa de Pós-Graduação em Planejamento Energético, COPPE, Universidade Federal do Rio de Janeiro, 2011.

Gandra, T. B. R. Elementos geomorfológicos e socioambientais como subsídios para a elaboração do Zoneamento Ecológico-Econômico Costeiro ZEEC. 178p. Rio Grande (RS), Dissertação (Mestrado) - Programa de Pós-Graduação em Oceanografia Física, Química e Geológica, Universidade Federal de Rio Grande (FURG), 2008.

Gil, A. C. Como elaborar projetos de pesquisa. São Paulo: Atlas, 1987. $159 \mathrm{p}$.

IBGE. Censo 2010. Consulta on-line em: $<$ https://censo2010.ibge.gov.br>. Acesso em: dez. 2017.

IOC - Intergovernmental Oceanographic Commission. A Handbook for Measuring the Progress and Outcomes of Integrated Coastal and Ocean Management. IOC Manuals and Guides, 46; ICAM Dossier, 2. Paris: UNESCO. 2006.

Jablonski, S.; Filet, M. Coastal management in Brazil: A political riddle. Ocean \& Coastal Management, 51, 536543, 2008.

Jannuzzi, P. M. Indicadores sociais no Brasil: conceitos, fontes de dados e aplicações. Campinas, SP: Alínea, 2005. $141 \mathrm{p}$.

Kerr, A. Canada's National Environmental Indicators Project. Sustainable Development and State of the Environmental. Reporting Branch, Environment Canada, Ottawa, 1994.

Leite, C. M. C. Ozoneamento ecológico-econômico: impasses e perspectivas de um instrumento de gestão ambiental. 140 p. Brasília, Dissertação (Mestrado) - Pós-Graduação em Geografia, Universidade de Brasília, 2001. 
Lima, A. Zoneamento Ecológico-Econômico: à luz dos direitos socioambientais. Disponível em: $<$ http://bdjur.stj. jus.br/dspace/handle/2011/2896>. 2006.

Marconi, M. A.; Lakatos, E. M. Técnicas de pesquisa. São Paulo: Atlas, 1985. 205 p.

Magalhães Júnior, A. P. Indicadores ambientais e recursos hídricos: realidade e perspectivas para o Brasil a partir da experiência francesa. 3. ed. Rio de Janeiro: Bertrand Brasil, 2011.

Mannis, A. Indicators of Sustainable Development. University of Ulster. Austria. 1996. Disponível em: $<$ http//:cesimo. ing.ula.ve/GAIA/Reports/indics.htm>.

Mitchell, G.; May, A.; McDonald, A. PICABUE: a methodological framework for the development of indicators of sustainable development. International Journal of Sustainable Development \& World Ecology, 2, 104-123, 1995.

Montaño, M.; Oliveira, I. S. D.; Ranieri, V. E. L.; Fontes, A. T.; Souza, N. T. O zoneamento ambiental e sua importância para a localização de atividades. Revista Pesquisa e Desenvolvimento Engenharia de Produção, 6, 49-64, 2007.

MMA - Ministério do Meio Ambiente. Consolidação da metodologia do ZEE para o Brasil. Transcrição dos debates. Brasília: Secretaria de Política para o Desenvolvimento Sustentável/SDS, 2002.

MMA - Ministério do Meio Ambiente. Diretrizes Metodológicas para o Zoneamento Ecológico-Econômico do Brasil. Brasília, DF, 2006.

MMA - Ministério do Meio Ambiente. Macrodiagnóstico da Zona Costeira e Marinha. Brasília, DF. 2008. 242 p.

MMA - Ministério do Meio Ambiente. O Zoneamento Econômico Ecológico na Amazônia Legal: trilhando o caminho do futuro. Brasília, DF, 2016. 100 p.

Ogata, M. G. EnvironmentalEconomic Zoning: A instrument for regulating territory in Brazil. Business and Management Review, SI, 4(7), 2015.

Oliveira, I. S. D. A contribuição do zoneamento ecológico econômico na avaliação de impacto ambiental: bases $e$ propostas conceituais. São Carlos, Dissertação (Mestrado) - Escola de Engenharia de São Carlos, Universidade de São
Paulo, 2004. DOI: 10.11606/D.18.2004.tde-09052005094619

Oliveira, A. C. A.; Souza, R. M. Geoindicadores socioambientais para monitoramento de dunas costeiras em Sergipe. RA'E GA, 14, 149-163, 2007.

Ranieri, V. E. L. Discussão das potencialidades e restrições do meio como subsídio para o zoneamento ambiental: o caso do município de Descalvado (SP). São Carlos, Dissertação (Mestrado) - Universidade de São Paulo, 2000.

Rechden Filho, R. Índice de qualidade de praia: o exemplo de Capão da Canoa, Rio Grande do Sul. 142p. Porto Alegre, Dissertação (Mestrado) - Programa de Pós-Graduação em Geologia Marinha, Universidade Federal do Rio Grande do Sul, 2005.

Santos, M. R. R. Critérios para análise do zoneamento ambiental como instrumento de planejamento e ordenamento territorial. 128 p. São Paulo, Dissertação (Mestrado) - Programa de Pós-Graduação em Engenharia Ambiental, Universidade de São Paulo, 2010.

Schubart, H. O. R. Zoneamento ecológico-econômico e a gestão dos recursos hídricos. In: Muñoz, H. R. Interfaces da gestão de recursos hídricos: desafios da lei de águas de 1997. Brasília: Secretaria de Recursos Hídricos, 2000. p.155-175.

Tavares, A. B.; Cruz, S. P. d.; Lollo, J. A. d. Geoindicadores para a caracterização de estados de diferentes ambientes. Estudos Geográficos, 42-57, 2007.

Triviños, A. N. S. Introdução à pesquisa em ciências sociais: a pesquisa qualitativa em educação. São Paulo: Atlas, $1987.69 \mathrm{p}$.

UNEP. Marine Plastic Debris and Microplastics: Global Lessons and Research to Inspire Action and Guide Policy Change. United Nations Environment Programme (UNEP), Nairobi (Retrieved from). 2016. Disponível em: <http:// ec.europa.eu/environment/marine/goodenvironmental-status/descriptor-10/pdf/Marine_plastic_debris_and_microplasticc technical_report_advance_copy.pdf $>$.

Vasconcelos, V. V.; Hadad, R. M.; Martins Junior, P. P. Zoneamento Ecológico-Econômico: objetivos e estratégias de política ambiental. Gaia Scientia, 7(1), 119-132, 2013. 
ANEXO 1 - Observações de desempenho dos indicadores utilizados na avaliação dos Zoneamentos Ecológico-Econômicos do Brasil.

\begin{tabular}{|c|c|c|c|}
\hline & Indicador & Função & Observações de desempenho \\
\hline 1 & $\begin{array}{l}\text { Base normativa estadual do } \\
\text { ZEEC }\end{array}$ & $\begin{array}{l}\text { Analisar a sustentação legal do } \\
\text { instrumento no estado. }\end{array}$ & $\begin{array}{l}\text { Demonstra ser de simples aplicação e traz dados de } \\
\text { relevância. Um problema observado é a necessidade } \\
\text { de especificar (na entrevista) a legislação referente ao } \\
\text { ZEEC e ao PEGC para obter homogeneidade no con- } \\
\text { teúdo das respostas, pois se observou, ao longo das } \\
\text { entrevistas, certo grau de confusão entre os entrevista- } \\
\text { dos, em que alguns já se referiram à legislação dos se- } \\
\text { tores e outros não se referiram à legislação de setores } \\
\text { em momento nenhum (embora existam setores com } \\
\text { ZEEC instituído). Sugere-se atrelar este indicador ao } \\
\text { indicador } 10 \text { (Número de setores costeiros (território) } \\
\text { com ZEEC). }\end{array}$ \\
\hline 2 & $\begin{array}{l}\text { Natureza da instituição res- } \\
\text { ponsável pelo ZEEC }\end{array}$ & $\begin{array}{l}\text { Identificar se o ZEEC é atrelado ao } \\
\text { órgão ambiental ou a outro setor. } \\
\text { Espera-se detalhar seu enfoque } \\
\text { e a relação com a realização de } \\
\text { zoneamentos do setor produtivo, a } \\
\text { abrangência e a integração do ZEEC. }\end{array}$ & $\begin{array}{l}\text { Não apresentou dificuldades em sua aplicação e trou- } \\
\text { xe resultados significativos. }\end{array}$ \\
\hline 3 & $\begin{array}{l}\text { Prioridade institucional do } \\
\text { ZEEC }\end{array}$ & $\begin{array}{l}\text { Demonstra a inserção e a prioriza- } \\
\text { ção do ZEEC na agenda política } \\
\text { estadual. }\end{array}$ & $\begin{array}{l}\text { Houve diferentes abordagens no momento da apli- } \\
\text { cação da pergunta, que se refletem na forma como } \\
\text { as respostas foram construídas, sendo que um estado } \\
\text { respondeu à pergunta dentro da lógica dos setores e } \\
\text { os outros dentro do estado como um todo. Sugere-se } \\
\text { simplificar o indicador, mantendo apenas as perguntas } \\
\text { sobre o grau de prioridade (mesmo guardada a subjeti- } \\
\text { vidade da questão) e a pergunta sobre a inserção do } \\
\text { ZEEC no orçamento estadual. }\end{array}$ \\
\hline 4 & $\begin{array}{l}\text { Representatividade interse- } \\
\text { torial no arranjo institucional } \\
\text { do ZEEC }\end{array}$ & $\begin{array}{l}\text { Analisa o arranjo institucional } \\
\text { quanto à participação dos setores } \\
\text { nas tomadas de decisões relativas } \\
\text { ao ZEEC. }\end{array}$ & $\begin{array}{l}\text { Eficiente na obtenção de dados sobre a existência de } \\
\text { espaços institucionais. Apresentou dificuldades em } \\
\text { obter informações sobre a distribuição dos represen- } \\
\text { tantes no grupo setorial, em função da dificuldade em } \\
\text { obter tal informação, principalmente dos processos } \\
\text { mais antigos. }\end{array}$ \\
\hline 5 & $\begin{array}{l}\text { Equipe técnica diretamente } \\
\text { envolvida na condução e na } \\
\text { elaboração do ZEEC }\end{array}$ & $\begin{array}{l}\text { Identifica a estrutura da equipe de } \\
\text { coordenação do ZEEC e o meio de } \\
\text { atuação dos responsáveis técnicos na } \\
\text { elaboração do ZEEC. } \\
\text { Relaciona-se à priorização/negligên- } \\
\text { cia de determinados critérios para a } \\
\text { elaboração do instrumento, eviden- } \\
\text { ciando a perspectiva e a intenção dos } \\
\text { gestores/tomadores de decisão no } \\
\text { tocante ao instrumento. }\end{array}$ & $\begin{array}{l}\text { Apesar de fornecer dados básicos sobre o tema, mos- } \\
\text { trou-se de difícil aplicação, pois envolveu dados técni- } \\
\text { cos que geralmente os entrevistados não possuíam e } \\
\text { que, muitas vezes, a memória institucional não era } \\
\text { contínua o suficiente para a obtenção do dado. } \\
\text { Sugere-se simplificar esse indicador, mantendo apenas } \\
\text { a questão sobre a natureza da equipe. }\end{array}$ \\
\hline 6 & $\begin{array}{l}\text { Dependência de recursos } \\
\text { humanos externos por fase } \\
\text { do ZEEC }\end{array}$ & $\begin{array}{l}\text { Analisar capacidade institucional } \\
\text { para elaboração do instrumento. }\end{array}$ & $\begin{array}{l}\text { Obteve respostas objetivas e claras, obtendo bom } \\
\text { desempenho. }\end{array}$ \\
\hline
\end{tabular}




\begin{tabular}{|c|c|c|c|}
\hline 7 & Fonte do Recurso & $\begin{array}{l}\text { Demonstra a capacidade de articu- } \\
\text { lação do órgão para obtenção do } \\
\text { recurso. Aponta as principais fontes } \\
\text { de recurso existentes para elaboração } \\
\text { no ZEEC no país. }\end{array}$ & $\begin{array}{l}\text { Obteve respostas objetivas no que diz respeito à } \\
\text { identificação de fontes de recurso. No que diz respeito } \\
\text { à capacidade de articulação, o levantamento foi com- } \\
\text { plexo, tanto em relação às respostas dos entrevistados } \\
\text { quanto na busca em referências bibliográficas e pro- } \\
\text { dutos oriundos dos zoneamentos. Quando o indicador } \\
\text { buscou definir valores investidos, o aporte dessas } \\
\text { informações foi relativamente baixo, uma vez que } \\
\text { alguns estados construíram seu ZEEC há muitos anos, } \\
\text { fazendo com que os valores se perdessem ou fossem } \\
\text { de difícil resgate na instituição. }\end{array}$ \\
\hline 8 & Limites territoriais do ZEEC & $\begin{array}{l}\text { Identificar se a base territorial do } \\
\text { ZEEC corresponde à legislação fede- } \\
\text { ral do Gerenciamento Costeiro. }\end{array}$ & $\begin{array}{l}\text { Obteve respostas relevantes para a análise das bases } \\
\text { territoriais utilizadas pelos estados, mas apresentou } \\
\text { problemas quanto à classificação de área abrangente } \\
\text { compatível ao Decreto } 5.300 / 2004 \text {, pois a posição dos } \\
\text { estados foi muito abrangente, sendo difícil definir com } \\
\text { precisão sua adequação ou não ao decreto. Poucos } \\
\text { citaram os limites marinhos. Sugere-se explicitar uma } \\
\text { nova pergunta para os limites terrestres e outra para os } \\
\text { limites marinhos. }\end{array}$ \\
\hline 9 & $\begin{array}{l}\text { Percentual da linha de costa e } \\
\text { da Zona Costeira com ZEEC }\end{array}$ & $\begin{array}{l}\text { Corrobora a avaliação da institu- } \\
\text { cionalização do instrumento em } \\
\text { território nacional, uma vez que indi- } \\
\text { ca uma primeira aproximação de um } \\
\text { diagnóstico de situação. }\end{array}$ & $\begin{array}{l}\text { Dado básico para a análise proposta. Para se analisar } \\
\text { um instrumento de gestão como o ZEEC, uma das } \\
\text { primeiras questões a ser identificadas é a existência do } \\
\text { mesmo nos estados. Mas, mesmo com essa importân- } \\
\text { cia, sugere-se simplificar as perguntas da entrevista, } \\
\text { uma vez que as mesmas exigiam um trabalho técnico } \\
\text { prévio e que nem sempre já se encontrava disponível, } \\
\text { sendo difícil para os entrevistados, bem como para a } \\
\text { equipe do projeto, obter essa informação com maior } \\
\text { precisão, seja em entrevistas ou na análise bibliográ- } \\
\text { fica. }\end{array}$ \\
\hline 10 & $\begin{array}{l}\text { Número de setores costeiros } \\
\text { (território) com ZEEC }\end{array}$ & $\begin{array}{l}\text { Corrobora a avaliação da institu- } \\
\text { cionalização do instrumento em } \\
\text { território nacional, uma vez que indi- } \\
\text { ca uma primeira aproximação de um } \\
\text { diagnóstico de situação. }\end{array}$ & $\begin{array}{l}\text { Fácil aplicação e de compreensão simples por parte } \\
\text { dos entrevistados. Seu maior problema é a interpre- } \\
\text { tação dos resultados, que necessita ser realizada de } \\
\text { forma integrada com o indicador } 9 \text {, uma vez que essa } \\
\text { análise pressupõe a relação entre número de setores, } \\
\text { extensão das zonas costeiras dos estados e existência } \\
\text { do instrumento. }\end{array}$ \\
\hline 11 & Escala cartográfica & $\begin{array}{l}\text { Importante para interface com } \\
\text { planos diretores, planos setoriais e } \\
\text { possível utilização em licenciamento } \\
\text { ambiental. }\end{array}$ & $\begin{array}{l}\text { Fácil aplicação, uma vez que a informação é direta. } \\
\text { A segunda parte do indicador visa identificar a escala } \\
\text { da linha de costa utilizada, bem como se houve } \\
\text { necessidade de compatibilizar a linha de costa adotada } \\
\text { na escala marinha com a adotada na escala terrestre. } \\
\text { Estas informações são de difícil acesso, tanto pelas } \\
\text { entrevistas quanto pelas análises de documentos, uma } \\
\text { vez que o tema tem forte caráter técnico e nem sempre } \\
\text { está discutido na literatura. }\end{array}$ \\
\hline
\end{tabular}




\begin{tabular}{|c|c|c|c|}
\hline 12 & $\begin{array}{l}\text { Articulação governamental no } \\
\text { processo do ZEEC }\end{array}$ & $\begin{array}{l}\text { Integração com as esferas de gover- } \\
\text { no, relação com o governo federal, } \\
\text { incentivo à implementação de } \\
\text { ZEECs municipais e a importância } \\
\text { da troca de informação com outros } \\
\text { estados. }\end{array}$ & $\begin{array}{l}\text { Aportou resultados interessantes ao relacionar os } \\
\text { diferentes níveis governamentais. Não houve maiores } \\
\text { dualidades em se obter a informação, mas deve-se } \\
\text { atentar para o fato de que, em estados onde a institu- } \\
\text { cionalização do GERCO é instável, há probabilidade } \\
\text { de o histórico institucional ser descontínuo, prejudi- } \\
\text { cando a obtenção desse dado. }\end{array}$ \\
\hline 13 & Participação social formal & $\begin{array}{l}\text { Entender o nível de envolvimento da } \\
\text { sociedade no processo. É relaciona- } \\
\text { do com a inserção e a relevância do } \\
\text { caráter social no ZEEC. }\end{array}$ & $\begin{array}{l}\text { Embora tenha sido proposto visando resposta objeti- } \\
\text { va, identificaram-se interpretações discordantes sobre } \\
\text { o mesmo. As dúvidas se deram em razão de o mesmo } \\
\text { avançar, em termos de análise, para o caráter da par- } \\
\text { ticipação (consultivo ou deliberativo) e/ou analisar a } \\
\text { sua efetividade (operacionalização e abrangência). } \\
\text { Para avaliações futuras, sugere-se desmembrar o mes- } \\
\text { mo em dois indicadores: } 1 \text { - Existe participação social } \\
\text { formal? Sim ou não. } 2 \text { - Com que caráter? Deliberati- } \\
\text { vo ou consultivo. }\end{array}$ \\
\hline 14 & $\begin{array}{l}\text { Composição da participação } \\
\text { social formal }\end{array}$ & $\begin{array}{l}\text { Entender a abrangência do caráter } \\
\text { social no processo. }\end{array}$ & $\begin{array}{l}\text { Embora demonstre ser simples, existem algumas } \\
\text { ressalvas entre as instituições em responder sobre as } \\
\text { características (cooperativas, sindicatos, associação } \\
\text { de bairro, ONGs - ambiental ou social, coletivos, } \\
\text { empresas) de cada instituição ou pessoas pelo fato } \\
\text { de não existir um padrão a ser seguido na política de } \\
\text { gestão costeira. }\end{array}$ \\
\hline 15 & $\begin{array}{l}\text { Mecanismos de participação } \\
\text { social no processo do ZEEC }\end{array}$ & $\begin{array}{l}\text { Verificar a participação social } \\
\text { durante as diferentes fases do ZEEC, } \\
\text { a fim de identificar quais métodos } \\
\text { utilizados. }\end{array}$ & $\begin{array}{l}\text { Este indicador, embora tenha aportado dados signi- } \\
\text { ficativos, é dependente do profundo conhecimento } \\
\text { dos técnicos envolvidos, uma vez que, em alguns } \\
\text { casos, o processo de elaboração do ZEEC é antigo, } \\
\text { dificultando o resgate da informação. A conceituação } \\
\text { empregada necessita ser bem definida, ou pode haver } \\
\text { confusão na hora do levantamento da informação. }\end{array}$ \\
\hline 16 & $\begin{array}{l}\text { Número e distribuição territo- } \\
\text { rial das Audiências Públicas }\end{array}$ & $\begin{array}{l}\text { Identifica a promoção de oportunida- } \\
\text { des para participação social de forma } \\
\text { amplamente distribuída no território. }\end{array}$ & $\begin{array}{l}\text { Eficiente na obtenção das informações acerca do } \\
\text { número de Audiências Públicas, mas nem tanto em } \\
\text { relação à sua distribuição territorial e nem em relação } \\
\text { ao número de participantes. } \\
\text { Há também necessidade de buscar uma definição } \\
\text { consensual sobre "audiência pública". }\end{array}$ \\
\hline 17 & $\begin{array}{l}\text { Consideração dos conflitos na } \\
\text { elaboração do ZEEC }\end{array}$ & $\begin{array}{l}\text { Possibilita um panorama dos temas } \\
\text { que mais vêm apresentando conflitos } \\
\text { no cenário nacional. }\end{array}$ & $\begin{array}{l}\text { O indicador permite listar os conflitos existentes, mas } \\
\text { foi pouco preciso na definição do caráter do conflito. } \\
\text { Outra questão é que houve interpretação dúbia por } \\
\text { parte dos entrevistados, que destoou da intenção do } \\
\text { indicador, uma vez que algumas respostas se confun- } \\
\text { diram com os conflitos habituais da zona costeira, } \\
\text { mesmo que muitas vezes sejam os próprios conflitos } \\
\text { impulsionadores da elaboração do ZEEC. }\end{array}$ \\
\hline
\end{tabular}




\begin{tabular}{|c|c|c|c|}
\hline 18 & $\begin{array}{l}\text { Compatibilidade metodoló- } \\
\text { gica por fases de elaboração } \\
\text { do ZEEC }\end{array}$ & $\begin{array}{l}\text { Identificar se a metodologia utilizada } \\
\text { para a elaboração do ZEEC seguiu } \\
\text { as diretrizes básicas do MMA. }\end{array}$ & $\begin{array}{l}\text { Falta de clareza entre os entrevistados em relação à } \\
\text { abrangência daquilo que se definiu como "metodolo- } \\
\text { gia do MMA". Tal confusão é parte do próprio instru- } \\
\text { mental metodológico disponível no país. Como todos } \\
\text { os estados fizeram adaptações em vista das múltiplas } \\
\text { realidades locais, define-se que não há um método } \\
\text { em si, e sim um conjunto de "bases" metodológicas, } \\
\text { fazendo com que as respostas nos diferentes estados } \\
\text { fossem de difícil correlação. }\end{array}$ \\
\hline 19 & $\begin{array}{l}\text { Metodologia para a faixa } \\
\text { marinha do ZEEC }\end{array}$ & $\begin{array}{l}\text { Considera a relevância da faixa } \\
\text { marinha para o processo de planeja- } \\
\text { mento e gestão no âmbito estadual. }\end{array}$ & $\begin{array}{l}\text { Permite identificar os estados com iniciativas de } \\
\text { ZEEC marinho e aponta, de forma descritiva, os dife- } \\
\text { rentes caminhos metodológicos adotados. }\end{array}$ \\
\hline 20 & Cartografia temática & $\begin{array}{l}\text { Analisa quais mapas temáticos } \\
\text { integraram o processo do ZEEC. } \\
\text { Demonstra a multiplicidade e a com- } \\
\text { plexidade de elementos que podem } \\
\text { compor um ZEEC. }\end{array}$ & $\begin{array}{l}\text { Apresenta resultados sobre a predominância de deter- } \\
\text { minados temas na configuração dos ZEECs. Sugere-s } \\
\text { a retirada da primeira pergunta desse indicador, a qual } \\
\text { solicita ao entrevistado uma lista de temas, as quais } \\
\text { necessitam atenção posterior à entrevista e não têm } \\
\text { relevância na análise. }\end{array}$ \\
\hline 21 & $\begin{array}{l}\text { Natureza dos dados para } \\
\text { elaboração do ZEEC }\end{array}$ & $\begin{array}{l}\text { Permite analisar a natureza do esfor- } \\
\text { ço de levantamento e/ou sistemati- } \\
\text { zação da informação, bem como a } \\
\text { qualidade dos dados. }\end{array}$ & $\begin{array}{l}\text { O indicador mostra de forma satisfatória a dependên- } \\
\text { cia de dados primários ou secundários para a elabo- } \\
\text { ração dos zoneamentos, mas não atinge a pretendida } \\
\text { relação de predominância entre os dois tipos de dados }\end{array}$ \\
\hline 22 & $\begin{array}{l}\text { Critério(s)-chave(s) na delimi- } \\
\text { tação das zonas-tipo e suas } \\
\text { diretrizes }\end{array}$ & $\begin{array}{l}\text { Demonstra a utilização de diagnós- } \\
\text { tico e prognóstico para o estabeleci- } \\
\text { mento das zonas-tipo e diretrizes. }\end{array}$ & $\begin{array}{l}\text { Focado na fonte dos critérios utilizados e se houve a } \\
\text { utilização dos produtos de diagnóstico e prognóstico } \\
\text { como fontes. } \\
\text { Sugere-se a reformulação do mesmo para uma lista de } \\
\text { opções onde o entrevistado apenas marca a opção que } \\
\text { melhor se encaixa no seu caso. }\end{array}$ \\
\hline 23 & $\begin{array}{l}\text { Compatibilização com zonea- } \\
\text { mentos setoriais }\end{array}$ & $\begin{array}{l}\text { Analisar a compatibilidade entre as } \\
\text { diretrizes do ZEEC e os zoneamen- } \\
\text { tos setoriais. }\end{array}$ & $\begin{array}{l}\text { O indicador mostrou-se eficiente na identificação de } \\
\text { sobreposição entre o ZEEC e os demais zoneamentos } \\
\text { existentes, bem como foi de fácil assimilação por } \\
\text { parte dos entrevistados. }\end{array}$ \\
\hline 24 & $\begin{array}{l}\text { Número de setores costeiros } \\
\text { (território) com ZEEC institu- } \\
\text { ído por ato normativo }\end{array}$ & $\begin{array}{l}\text { Avaliar a sustentação legal para a } \\
\text { implementação do instrumento. }\end{array}$ & $\begin{array}{l}\text { O indicador mostrou-se simples e eficiente na identifi- } \\
\text { cação de leis e normas que indiquem uma sustentação } \\
\text { legal para a implementação do instrumento. }\end{array}$ \\
\hline 25 & $\begin{array}{l}\text { Fase em que se encontra o } \\
\text { ZEEC }\end{array}$ & $\begin{array}{l}\text { Em caso de ZEEC em elaboração ou } \\
\text { em revisão, verificar em que fase se } \\
\text { encontra. }\end{array}$ & $\begin{array}{l}\text { O indicador foi eficiente para a observação quan- } \\
\text { titativa da relação do ZEEC com a fase que ele se } \\
\text { encontra no que toca à sua concepção. A forma como } \\
\text { a informação foi obtida ocasionou certa redundância } \\
\text { em relação a um estado ter mais de um setor costeiro } \\
\text { com ZEEC em diferentes fases. }\end{array}$ \\
\hline 26 & $\begin{array}{l}\text { Nível de elaboração do ZEE } \\
\text { na faixa marinha da Zona } \\
\text { Costeira }\end{array}$ & $\begin{array}{l}\text { Busca-se retratar um quadro da } \\
\text { situação do ZEEC na faixa marinha } \\
\text { no país, quanto à sua elaboração. }\end{array}$ & $\begin{array}{l}\text { O indicador foi eficiente para a observação quantita- } \\
\text { tiva da relação do ZEEC marinho com a fase em que } \\
\text { ele se encontra no que toca à sua concepção, bem } \\
\text { como com a relação entre a existência de normas e a } \\
\text { elaboração do mesmo. } \\
\text { As demais questões inclusas no indicador (rela- } \\
\text { cionadas a licenciamento e políticas setoriais) não } \\
\text { aportaram resultados significativos para avaliação do } \\
\text { instrumento. }\end{array}$ \\
\hline
\end{tabular}




\begin{tabular}{|c|c|c|c|}
\hline 27 & Produtos gerados pelo ZEEC & $\begin{array}{l}\text { Destaca a abrangência de produtos } \\
\text { e a própria concepção do ZEEC no } \\
\text { âmbito estadual. }\end{array}$ & $\begin{array}{l}\text { O indicador, embora tenha sido eficiente na de- } \\
\text { monstração da pluralidade dos produtos gerados, } \\
\text { mostrou-se pouco eficaz quanto à precisão do caráter } \\
\text { dos mesmos, no sentido de diferenciá-los como } \\
\text { inerentes ao processo (mapas e relatórios) daqueles } \\
\text { que cumprem o papel de comunicação do ZEEC junto } \\
\text { à sociedade. }\end{array}$ \\
\hline 28 & $\begin{array}{l}\text { Clareza dos produtos gerados } \\
\text { pelo ZEEC }\end{array}$ & $\begin{array}{l}\text { Aponta uma maior facilidade para } \\
\text { interpretação, divulgação e utiliza- } \\
\text { ção do instrumento. }\end{array}$ & $\begin{array}{l}\text { O indicador pode apresentar certo grau de dependên- } \\
\text { cia para a percepção dos gestores envolvidos com } \\
\text { a elaboração e a implementação do instrumento. O } \\
\text { conceito de "clareza" possui considerável grau de } \\
\text { subjetividade, podendo dificultar sua aplicação e sua } \\
\text { interpretação. Sugere-se alteração para "facilidade de } \\
\text { compreensão para a tomada de decisão", o que poderá } \\
\text { reduzir essa subjetividade. }\end{array}$ \\
\hline 29 & Acesso à informação & $\begin{array}{l}\text { Relacionado aos princípios da } \\
\text { transparência, visibilidade e acesso à } \\
\text { informação. }\end{array}$ & $\begin{array}{l}\text { Eficiente na identificação do grau de acesso à infor- } \\
\text { mação derivada dos processos de ZEEC nos estados, } \\
\text { sendo possível ainda inferir a relação entre a matu- } \\
\text { ridade do processo X acessibilidade da informação. } \\
\text { Não houve maiores dificuldades para a obtençąo dos } \\
\text { dados referentes a este indicador. }\end{array}$ \\
\hline 30 & $\begin{array}{l}\text { Diretrizes, plano de ação e } \\
\text { metas do ZEEC }\end{array}$ & $\begin{array}{l}\text { Analisa se os produtos finais do } \\
\text { ZEEC indicam diretrizes, plano de } \\
\text { ação e/ou metas para cada zona. }\end{array}$ & $\begin{array}{l}\text { Eficiente e direto na obtenção das informações acerca } \\
\text { da existência de diretrizes, metas e ações no escopo } \\
\text { dos ZEEC. Destaca-se que não houve a intenção de } \\
\text { buscar grau de eficiência das mesmas e nem avaliar } \\
\text { de forma qualitativa nenhuma dessas iniciativas. Não } \\
\text { houve interpretações dúbias por parte dos gestores } \\
\text { e nem dos técnicos envolvidos no projeto sobre a } \\
\text { conceituação utilizada. }\end{array}$ \\
\hline 31 & $\begin{array}{l}\text { Consideração do ZEEC nas } \\
\text { políticas setoriais (setor pro- } \\
\text { dutivo) do estado }\end{array}$ & $\begin{array}{l}\text { Identifica se as políticas ambientais } \\
\text { setoriais consideram o ZEEC. }\end{array}$ & $\begin{array}{l}\text { Eficiente e direto na obtenção das informações acerca } \\
\text { da inserção e consideração do ZEEC em políticas do } \\
\text { setor produtivo. Porém, cabe ressaltar que, para uma } \\
\text { melhor aferição da qualidade das informações obtidas } \\
\text { neste indicador, foi necessária uma profunda pesquisa } \\
\text { em diversas instituições dos governos estaduais, uma } \\
\text { vez que a informação é pautada, inicialmente, na opi- } \\
\text { nião do entrevistado, o qual é passível de desconhe- } \\
\text { cimento de alguma iniciativa com o caráter almejado } \\
\text { neste indicador. }\end{array}$ \\
\hline 32 & $\begin{array}{l}\text { Consideração do ZEEC nas } \\
\text { políticas territoriais e ambien- } \\
\text { tais do estado }\end{array}$ & $\begin{array}{l}\text { Verificar internalização e relevância } \\
\text { do ZEEC nas políticas territoriais e } \\
\text { ambientais estaduais. }\end{array}$ & $\begin{array}{l}\text { Eficiente na obtenção das informações acerca da } \\
\text { inserção e consideração do ZEEC em políticas territo- } \\
\text { riais e ambientais do estado. Porém, cabe ressaltar que } \\
\text { no âmbito do questionário uma das perguntas - "De } \\
\text { que forma se dá a integração do ZEE do estado com o } \\
\text { ZEEC?" - mostrou-se complexa para a obtenção das } \\
\text { informações desejadas nesse indicador. }\end{array}$ \\
\hline
\end{tabular}




\begin{tabular}{|l|l|l|l|}
\hline 33 & $\begin{array}{l}\text { Utilização do ZEEC no licen- } \\
\text { ciamento ambiental }\end{array}$ & $\begin{array}{l}\text { Identificar as formas de utilização } \\
\text { do instrumento em relação aos pro- } \\
\text { cessos inerentes ao Licenciamento } \\
\text { Ambiental no estado. }\end{array}$ & $\begin{array}{l}\text { Eficiente na obtenção das informações acerca da } \\
\text { utilização do ZEEC no licenciamento ambiental no } \\
\text { estado. Porém, cabe ressaltar que o indicador tem } \\
\text { como uma de suas finalidades "Identificar as formas } \\
\text { de utilização do instrumento em relação aos processos } \\
\text { inerentes ao Licenciamento Ambiental no estado". } \\
\text { Para que tal meta fosse plenamente atingida, seriam } \\
\text { necessárias alterações no escopo do indicador, ou } \\
\text { ainda alteração nas perguntas formuladas. }\end{array}$ \\
\hline 34 & $\begin{array}{l}\text { Capacitação para o ZEEC } \\
\text { e a melhor compreensão e utilização } \\
\text { do ZEEC na esfera governamental. }\end{array}$ & $\begin{array}{l}\text { Eficiente na obtenção das informações acerca da } \\
\text { capacitação de gestores para o ZEEC, uma vez que } \\
\text { foi possível identificar os estados que passaram por } \\
\text { processos de capacitação. Porém, a forma como o } \\
\text { indicador está expresso dificulta a análise do fluxo } \\
\text { dessa capacitação: o estado foi capacitado ou oferece } \\
\text { capacitação? Ou ambos? }\end{array}$ \\
\hline 35 & $\begin{array}{l}\text { Monitoramento e avaliação de } \\
\text { metas e diretrizes do ZEEC }\end{array}$ & $\begin{array}{l}\text { Analisa se as diretrizes gerais ou me- } \\
\text { tas para cada zona foram atingidas. }\end{array}$ & $\begin{array}{l}\text { Eficiente na obtenção das informações acerca do } \\
\text { monitoramento e da avaliação de metas e diretrizes } \\
\text { do ZEEC. }\end{array}$ \\
\hline
\end{tabular}

